
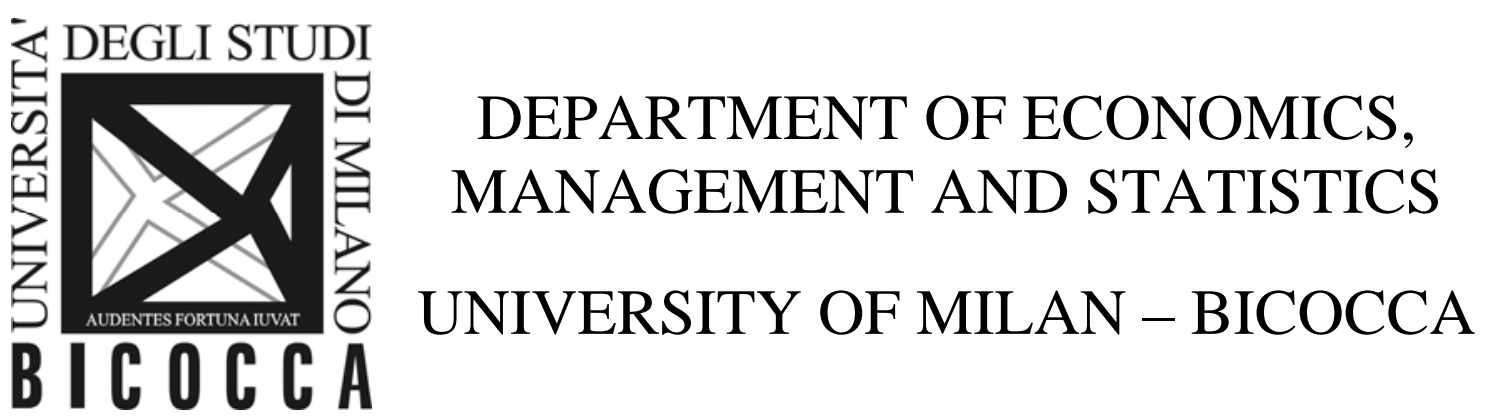

DEMS WORKING PAPER SERIES

\title{
Forecasting in a DSGE Model with Banking Intermediation: Evidence from the US
}

Roberta Cardani, Alessia Paccagnini, Stefania Villa

No. 292 - February 2015

Dipartimento di Economia, Metodi Quantitativi e Strategie di Impresa Università degli Studi di Milano - Bicocca

http://dems.unimib.it/ 


\title{
Forecasting in a DSGE Model with Banking Intermediation:
}

\author{
Evidence from the US*
}

\author{
Roberta Cardani $^{\dagger} \quad$ Alessia Paccagnini ${ }^{\ddagger} \quad$ Stefania Villa ${ }^{\S}$
}

9th February 2015

\begin{abstract}
This paper examines the forecasting performance of DSGE models with and without banking intermediation for the US economy. Over the forecast period 2001-2013, the model augmented with a banking sector leads to an improvement of point and density forecasts for inflation and the short term interest rate, while the better forecast for output depends on the forecasting horizon/period. To interpret this finding it is crucial to take into account parameters instabilities showed by a recursive-window estimation. Moreover, rolling estimates of point forecasts show that a banking sector helps improving the forecasting performance of output and inflation in the recent period.
\end{abstract}

Keywords: Bayesian estimation, Forecasting, Banking sector

JEL code: C11, C13, C32, E37

\footnotetext{
*We are grateful to Fabio Canova, Efrem Castelnuovo, Francesco Furlanetto, Paolo Gelain, Barbara Rossi, Herman van Dijk, and to conference participants at the 2015 ASSA Meetings in Boston, SNDE 2014 conference in New York, CEF 2014 in Oslo, Advances in Applied Macro-Finance and Forecasting 2014 in Istanbul, CFE 2014 in Pisa, 2014 EC2 conference "Advances in Forecasting" in Barcelona for their insightful comments. All remaining errors are ours. Cardani and Paccagnini acknowledge financial support from the RastaNews project funded by the European Community's 7th Framework Program (FP7).

${ }^{\dagger}$ DEMS department, University of Milano-Bicocca. Email: roberta.cardani@unimib.it.

${ }^{\ddagger}$ DEMS department, University of Milano-Bicocca. Email: alessia.paccagnini@unimib.it

${ }^{\S}$ Department of Economics, University of Foggia and Center fot Economic Studies, KU Leuven. Email: stefania.villa@unifg.it
} 


\section{Introduction}

Financial intermediaries have played a central role in the recent financial crisis by affecting the supply of credit in the economy. Ciccarelli et al. (2010) find empirical evidence that during the crisis the crunch in the credit provision to firms contributes significantly to the GDP reduction both in the Euro area and the US. In addition, the role of the financial sector is important because it can be itself a source of shocks. Fornari and Stracca (2012) estimate a panel VAR for advanced economies, where financial shocks (i.e. shocks to the financial sector) are identified through sign restrictions. They conclude that these shocks have a significant influence on key macroeconomic variables both in normal and crisis times. However, most prominent macroeconomic models assume perfectly competitive financial markets (e.g. Smets and Wouters, 2007) until recently.

Before the Great Recession, the dynamic stochastic general equilibrium (DSGE) models proposed by Bernanke et al. (1999) and Iacoviello (2005) consider financial frictions only on the borrower's side of credit markets. Under these settings, borrowers can obtain funds directly from lenders without any active role for financial intermediaries. In the wake of the financial turmoil understanding the disruption in financial intermediation has become a priority for both academics and policy makers. The DSGE literature on financial intermediation is indeed growing (see Brunnermeier et al., 2013, for a survey). In the model by Gertler and Karadi (2011) an endogenous leverage constraint on banks effectively ties the provision of credit to the real economy. This mechanism creates a loop between financial intermediaries' balance sheet, firms' asset prices and GDP. In comparison to other DSGE models with a banking sector, their model features an agency problem which poses a limit to the financial intermediaries ability to acquire assets, and hence, to lend to the private sector. In addition, it is fairly elegant and computationally fairly tractable (Cole, 2011).

The main focus of this paper is to evaluate empirically the role of financial intermediaries for the US economy from a forecasting viewpoint. To this end, we compare the workhorse Smets and Wouters (2007) model (hereafter, SW) with a SW economy augmented by a banking sector as in Gertler and Karadi (2011) (hereafter, SWBF).

The forecasting literature has partly assessed the empirical relevance of DSGE models 
with financial frictions for the US economy. Del Negro and Schorfheide (2013) show, among other things, that a Smets and Wouters (2007) economy augmented by financial frictions à la Bernanke et al. (1999) (BGG) can forecast output growth during the Great Recession better than the SW model, while the latter model generates more accurate forecasts in previous times. Villa (2015) compares, among other things, the forecasting performance of two DSGE models, one featuring financial frictions as in BGG and the other as in Gertler and Karadi (2011). She finds that no model dominates the other in terms of forecasting accuracy since the root mean square forecast errors are remarkably similar across the two models. Kolasa and Rubaszek (2015) find that adding frictions in the housing sector proves very helpful during the financial turmoil, providing a forecasting performance better than both the frictionless benchmark and the alternative that incorporates financial frictions in the corporate sector.

Differently from them, we focus on the role of financial intermediation in forecasting real and nominal variables. Using Bayesian techniques, we recursively estimate the SW and SWBF models. The out-of-sample forecasting period is from 2001Q1 to 2013Q4, split into two subsamples: 2001Q1-2008Q4 and 2009Q1-2013Q4. The point forecast analysis, based on Mean Absolute Errors (MAE) and Root Mean Square Forecast Error (RMSFE), and the density forecast evaluation, based on the average of the log predictive density scores (LPDS) and the probability integral transform (PIT) histograms, shows that there is no clear evidence of an outperformed model in terms of forecasting accuracy. In the first sample - 2001Q1-2008Q4 - the SWBF model exhibits the best performance for output growth and inflation only in the longer horizon, whereas in the second sample - 2009Q1-2013Q4 - the SWBF model outperforms the SW model in forecasting inflation and the short term interest rates, but not output growth. In order to rationalize these results, we investigate possible instabilities in parameters. The literature offers at least three different approaches to deal with parameters instability: i) time-varying coefficients/ stochastic volatilities (e.g. Fernández-Villaverde et al., 2010; Caldara et al., 2012; Bekiros and Paccagnini, 2013); ii) Markov-switching DSGE modeling (e.g. Eo, 2009; Bianchi, 2013; Foerster et al., 2014); and iii) rolling-window estimation (e.g. Castelnuovo, 2012; Hurtado, 2014). We follow the last approach and employ a recursive estimation of the DSGE models. We find a regime change in the SW model, while 
the change is less evident in the SWBF model due to its richer modelling structure. The variation in the estimation of shocks and parameters implies that the role of shocks in affecting macroeconomic variables is also changing over time and across models' specification.

In addition, by computing the rolling RMSFE as in Del Negro and Schorfheide (2013), we observe that there are some quarters in which the SWBF model outperforms the SW model for both output growth and inflation. Hence, the empirical ranking among models changes over time.

The reminder of the paper is organized as follows. Section 2 briefly sketches the SW and SWBF models. The Bayesian estimation procedure is discussed in Section 3. Section 4 evaluates the forecasting accuracy. Section 5 concludes. An appendix complements the paper by providing technical details about the construction of the dataset and robustness exercises of forecasting accuracy.

\section{The fully-fledged DSGE model}

This section briefly describes two non-nested models: the linearized version of the model by Gertler and Karadi (2011), that is included in an otherwise setup of Smets and Wouters (2007), and the SW model.

The economy is composed by households, labor unions, labor packers, financial intermediaries, a productive sector and a monetary authority. Households consume, accumulate government bonds and supply labor. A labor union differentiates labor and sets wages in a monopolistically competitive market. Competitive labor packers buy labor services from the union, package and sell them to intermediate goods firms. Output is produced in several steps, including a monopolistically competitive sector with producers facing price rigidities. The monetary authority sets the short-term interest rate according to a Taylor rule. In the SWBF model, the presence of an agency problem limits the ability of financial intermediaries to obtain deposits from households. This, in turn, affects the leverage ratio of financial intermediaries. 
Households. The economy is populated by a continuum of households of measure unity. Within each household there are two types of members: a share $f$ are workers while a share $1-f$ are bankers. The first earn wages while the latter manage financial intermediaries. The maximization problem of households yields the following Euler equation: ${ }^{1}$

$$
c_{t}=c_{1} c_{t-1}+\left(1-c_{1}\right) E_{t} c_{t+1}+c_{2}\left(l_{t}-E_{t} l_{t+1}\right)-c_{3}\left(r_{t}-E_{t} \pi_{t+1}+e_{t}^{b}\right),
$$

where $c_{1}=\frac{h / \gamma}{1+h / \gamma}, c_{2}=\frac{\left(\sigma_{c}-1\right)\left(w_{*} l_{*} / c_{*}\right)}{\sigma_{c}(1+h / \gamma)}$ and $c_{3}=\frac{1-h / \gamma}{\sigma_{c}(1+h / \gamma)}$. The parameter $h$ measures the degree of superficial external habits in consumption, $\sigma_{c}$ the coefficient of relative risk aversion of households, $\gamma$ is the steady state growth rate and $e_{t}^{b}$ captures the risk premium shock following an $\mathrm{AR}(1)$ process, $\rho_{e}$ is an autoregressive coefficient and $\varepsilon_{t}^{e} \sim N\left(0, \sigma_{e}^{2}\right)$. Current consumption, $c_{t}$, is affected by past and future consumption, $c_{t-1}, E_{t} c_{t+1}$, expected increasing growth hours $\left(l_{t}-E_{t} l_{t+1}\right)$ and the real interest rate $\left(r_{t}-E_{t} \pi_{t+1}\right)$.

Labor market. Wage setting is characterized by sticky wages, as shown by:

$$
w_{t}=w_{1} w_{t-1}+\left(1-w_{1}\right)\left(E_{t} w_{t+1}+E_{t} \pi_{t+1}\right)-w_{2} \pi_{t}+w_{3} \pi_{t-1}-w_{4} \mu_{t}^{w}+e_{t}^{w},
$$

where $w_{1}=\frac{1}{1+\beta \gamma^{1-\sigma_{c}}}, w_{2}=\frac{1+\beta \gamma^{1-\sigma_{c} \iota_{w}}}{1+\beta \gamma^{1-\sigma_{c}}}, w_{3}=\frac{\iota_{w}}{1+\beta \gamma^{1-\sigma_{c}}}$ and $w_{4}=\frac{\left(1+\xi_{w} \beta \gamma^{1-\sigma_{c}}\right)\left(1-\xi_{w}\right)}{\left(1+\beta \gamma^{1-\sigma_{c}}\right) \xi_{w}\left[\left(\phi_{w}-1\right) e^{w}+1\right]}$. The parameter $\beta$ represents the households discount factor, $\xi_{w}$ indicates the Calvo probability of not adjusting nominal wages, $\iota_{w}$ denotes the degree of wage indexation of non-adjusting unions, $\left(\phi_{w}-1\right)$ is the steady state labor market markup, and $e^{w}$ is the curvature of the Kimball aggregator in the labor market. The wage markup disturbance, $e_{t}^{w}=\rho_{w} e_{t-1}^{w}+\varepsilon_{t}^{w}-$ $\mu_{w} \varepsilon_{t-1}^{w}$, is an exogenous shock to the wage markup following an $\operatorname{ARMA}(1,1)$ process, $\rho_{w}$ is an autoregressive coefficient and $\varepsilon_{t}^{w} \sim N\left(0, \sigma_{w}^{2}\right)$.

The wage mark-up is the difference between the real wages and the marginal rate of substitution between consumption and labor:

$$
\mu_{w}=w_{t}-\left[\sigma_{l} l_{t}+\frac{1}{1-h}\left(c_{t}-h c_{t-1}\right)\right]
$$

\footnotetext{
${ }^{1}$ All variables are log-linearized around their steady state balanced growth path and starred variables represent steady state values.
} 
where $\sigma_{l}$ is the elasticity of labor supply with respect to the real wage.

Production sector. The production sector is characterized by different types of firms. A continuum of infinitely-lived intermediate firms of measure one produce an intermediate good using labor and capital under perfect competition. They use a standard Cobb-Douglas production function, according to:

$$
y_{t}=\phi_{p}\left[\alpha\left(k_{t-1}+u_{t}\right)+(1-\alpha) l_{t}\right]+e_{t}^{a},
$$

where $u_{t}$ is capital utilization, $e_{t}^{a}$ is the transitory technology shock following an $\operatorname{AR}(1)$ process, $\rho_{a}$ is an autoregressive coefficient and $\varepsilon_{t}^{a} \sim N\left(0, \sigma_{a}^{2}\right)$. The parameter $\phi_{p}$ represents one plus the share of fixed costs in production.

The optimal rate of utilization, $u_{t}$, depends on the marginal product of capital, $z_{t}^{k}$, as follows:

$$
u_{t}=u_{1} z_{t}^{k}
$$

with $u_{1}=\frac{(1-\psi)}{\psi}$, where $\psi$ represents the positive function of elasticity of the capital utilization adjustment cost.

A continuum of retail firms differentiate intermediate goods and set prices following a process à la Calvo (1983), in analogy to the labor market:

$$
\pi_{t}=\pi_{1} \pi_{t-1}+\pi_{2} \pi_{t+1}-\pi_{3} \mu_{t}^{p}+e_{t}^{p},
$$

with $\pi_{1}=\frac{\iota_{p}}{1+\beta \gamma^{1-\sigma_{c \iota_{p}}}}, \pi_{2}=\frac{\beta \gamma^{1-\sigma_{c}}}{1+\beta \gamma^{1-\sigma_{\iota_{\iota_{p}}}}}, \pi_{3}=\frac{\left(1-\beta \gamma^{1-\sigma_{c}} \xi_{p}\right)\left(1-\xi_{p}\right)}{\left(1+\beta \gamma^{\left.1-\sigma_{c \iota_{p}}\right) \xi_{p}}\left[\left(\phi_{p}-1\right) e^{p}+1\right]\right.}, \iota_{p}$ represents the indexation parameter, $\xi_{p}$ the degree of price stickiness in goods market and $e^{p}$ is curvature of Kimball aggregator in the goods market. The price markup disturbance follows an $\operatorname{ARMA}(1,1)$ process, $e_{t}^{p}=\rho_{p} e_{t-1}^{p}+\varepsilon_{t}^{p}-\mu_{p} \varepsilon_{t-1}^{p}, \rho_{p}$ is the $\operatorname{AR}(1)$ coefficient and $\varepsilon_{t}^{p} \sim N\left(0, \sigma_{p}^{2}\right)$. The term $\left(\phi_{p}-1\right)$ is the steady-state markup in the goods market.

The price markup, $\mu_{p}$, is equal to the difference between the marginal product of labor and the real wage:

$$
\mu_{p}=\alpha\left(k_{t-1}+u_{t}-l_{t}\right)+e_{t}^{a}-w_{t}
$$


Cost minimization by firms implies that the marginal product of capital is negatively related to the capital-labor ratio and real wages:

$$
z_{t}^{k}=-\left(k_{t-1}+u_{t}-l_{t}\right)+w_{t}
$$

A continuum of competitive capital goods producers repair depreciated capital and rebuild new productive capital. Capital producers purchase depreciated capital from the intermediate-goods producers and combine it with investment goods to produce new capital. The newly produced capital is sold back to intermediate goods firms and any profits are transferred to households. The investment is subject to adjustment costs as in Christiano et al. (2005):

$$
i_{t}=i_{1} i_{t-1}+\left(1-i_{1}\right) E_{t} i_{t+1}+i_{2} q_{t}+e_{t}^{x}
$$

where $i_{1}=\frac{1}{\left(1+\beta \gamma^{\left.1-\sigma_{c}\right)}\right.}$ and $i_{2}=\frac{i_{1}}{\gamma^{2} \varphi}$. The parameter $\varphi$ is the elasticity of investment adjustment costs and $e_{t}^{x}$ is an investment-specific technology shock following an $\mathrm{AR}(1)$ process with $\rho^{x}$ the $\operatorname{AR}(1)$ coefficient and $\varepsilon_{t}^{x} \sim N\left(0, \sigma_{x}^{2}\right)$.

The arbitrage equation for the value of capital is given by:

$$
E_{t} r_{t+1}^{k}=q_{1} E_{t} z_{t+1}^{k}+q_{2} E_{t} q_{t+1}-q_{t},
$$

where $q_{1}=\frac{z_{*}^{k}}{r_{*}^{k}}, q_{2}=\frac{(1-\delta)}{r_{*}^{k}+(1-\delta)}=\beta \gamma^{1-\sigma_{c}}(1-\delta)$. The parameter $\delta$ represents the depreciation rate and $E_{t} r_{t+1}^{k}$ is the rental rate of capital.

The law of motion of installed capital evolves as follows:

$$
k_{t}=k_{1} k_{t-1}+\left(1-k_{1}\right) i_{t}+k_{2} e_{t}^{x},
$$

where $k_{1}=\frac{(1-\delta)}{\gamma}$ and $k_{2}=\left[1-\frac{(1-\delta)}{\gamma}\right]\left(1+\beta \gamma^{1-\sigma_{c}}\right) \gamma^{2} \varphi$. 
Monetary authority. The central bank sets the nominal interest rate according to a Taylor rule of the form:

$$
r_{t}=\rho_{r} r_{t-1}+\left(1-\rho_{r}\right)\left[\rho_{\pi} \pi_{t}+\rho_{y}\left(y_{t}-y_{t}^{p}\right)\right]+\rho_{\Delta y}\left[\left(y_{t}-y_{t}^{p}\right)-\left(y_{t-1}-y_{t-1}^{p}\right)\right]+e_{t}^{i},
$$

where $r_{t}$ is the gross nominal interest rate, $y_{t}^{p}$ represents the level of output that would prevail under flexible prices and wages, $\rho_{r}, \rho_{\pi}, \rho_{y}$ and $\rho_{\Delta y}$ are policy parameters referring to interestrate smoothing, and the responsiveness of the nominal interest rate to inflation, to the output gap and to changes in the output gap, respectively. The term $e_{t}^{i}$ represents an exogenous shock following an $\operatorname{AR}(1)$ process, $\rho_{i}$ is an autoregressive coefficient and $\varepsilon_{t}^{i} \sim N\left(0, \sigma_{i}^{2}\right)$.

Financial intermediaries. In the SWBF model, a continuum of mass-one banks owned by the households lend funds to non financial sector. The balance sheet of the risk-neutral financial institution features assets, $s_{t} q_{t}-s_{t}$ is the quantity of financial claims on non-financial firms and $q_{t}$ is the relative price of each claim - and net worth $n_{t}$ as well as deposits, $b_{t}$, on the liabilities side.

As each financial intermediary pays an interest the risk free interest rate on deposits, $r_{t}$, and receives on loans $E_{t} r_{t+1}^{k}$, a credit spread $r_{t}^{e p}$ arises:

$$
r_{t}^{e p}=E_{t} r_{t+1}^{k}-\left(r_{t}-E_{t} \pi_{t+1}\right) .
$$

To limit the liability of financial intermediaries a moral-hazard costly enforcement problem occurs so that they cannot borrow indefinitely from households. At the beginning of each period the banker can choose to divert the fraction $\phi$ of available funds from the project and transfer them back to their household. Depositors can force the intermediary into bankruptcy and recover the remaining fraction $1-\phi$ of total assets. However, costly enforcement implies that it is too costly for the depositors to recover the diverted fraction of funds by the banker. To limit the expansion of bankers' assets, a positive exit probability prevents bankers from accumulating sufficient net worth to finance equity investment internally. In each period $1-\varpi$ bankers exit and transfer their earning back to their corresponding households. Those 
bankers are replaced by an equal number of workers who are endowed by start-up funds, $\xi$, by their households. The amount of assets that financial intermediaries can acquire depends on the equity capital:

$$
q_{t}+k_{t}=l e v_{t}+n_{t}
$$

where the leverage, levt, is endogenously determined as

$$
l e v_{t}=\eta_{t}+\frac{v}{\phi-v} v_{t}
$$

Note that the leverage depends both on the the gain of having net worth, $\eta_{t}$, and on the gain of expanding assets, $v_{t}$. The first is specified as follows:

$$
\eta_{t}=\eta_{1}\left(E_{t} \Lambda_{t+1}-\Lambda_{t}+z_{t}+E_{t} \eta_{t+1}\right)
$$

where $\eta_{1}=\frac{\varpi \beta}{\gamma^{\sigma_{c}}} z_{*}$ and $\Lambda_{t}$ is the Lagrange multiplier associated to the utility maximization problem. The gross growth rate of net worth, $z_{t}$, is represented by

$$
z_{t}=z_{1} r_{t}^{k}+z_{2}\left(r_{t-1}-\pi_{t}\right)+z_{3} l e v_{t-1}
$$

where $z_{1}=\frac{l e v_{*} r_{*}^{k}}{z_{*}}, z_{2}=r_{*}\left(1-l e v_{*}\right)$ and $z_{3}=l e v_{*}\left(r_{*}^{k}-r_{*}\right)$.

The gain of expanding assets, $v_{t}$, can be expressed as:

$$
v_{t}=v_{1}\left(E_{t} \Lambda_{t+1}-\Lambda_{t}+x_{t}+E_{t} v_{t+1}\right)+v_{2}\left[r_{*}^{k} r_{t}^{k}-r_{*}\left(r_{t-1}-\pi_{t}\right)\right]+v_{3}\left(E_{t} \Lambda_{t+1}-\Lambda_{t}\right)
$$

where $v_{1}=\frac{\varpi \beta}{\gamma^{\sigma_{c}}} z_{*}, v_{2}=\frac{(1-\varpi) \beta}{\gamma^{\sigma} \nu_{*}}, v_{3}=\frac{(1-\varpi) \beta}{\gamma^{\sigma} \nu_{*}}\left(r_{*}^{k}-r_{*}\right)$. The gross growth rate in assets, $x_{t}$, is

$$
x_{t}=l e v_{t}-l e v_{t-1}+z_{t} .
$$

Finally, total net worth, $n_{t}$, is composed by the sum of the net worth of existing bankers, $n_{t}^{e}$, and the net worth of new bankers, $n_{t}^{n}$ :

$$
n_{t}=n_{1} n_{t}^{e}+n_{2} n_{t}^{n},
$$


where $n_{1}=\frac{n_{*}^{e}}{n}$ and $n_{2}=\frac{n_{*}^{n}}{n}$. The law of motion of the net worth of existing bankers depends on the gross growth of net worth and on exogenous shock, $e_{t}^{n}$, to the net worth of banks following an $\mathrm{AR}(1)$ process, $\rho_{n}$ is an autoregressive coefficient and $\varepsilon_{t}^{n} \sim N\left(0, \sigma_{n}^{2}\right)$ :

$$
n_{t}^{e}=n_{t-1}^{e}+z_{t}+e_{t}^{n}
$$

New bankers receive a "start-up" transfer from households, equal to a fraction $\xi$ of total assets. Therefore, their net worth is:

$$
n_{t}^{n}=\xi l e v_{*}\left(q_{t}+k_{t}\right)
$$

Equilibrium. Equilibrium conditions in labor and goods market require that the resource constraint is satisfied in every period:

$$
y_{t}=c_{y} c_{t}+i_{y} i_{t}+z_{y} z_{t}^{k}+e_{g}
$$

where $c_{y}$ is the steady state share of consumption, $i_{y}$ the steady state share of investment, $z_{y}=z_{*}^{k} k_{*} / y_{*}$ represents the steady-state rental rate of capital, and $e_{g}$ exogenous government spending disturbance that follows an $\mathrm{AR}(1)$ process and it is also affected by the technology shock as in Smets and Wouters (2007), with $\rho_{g}$ is the AR coefficient and $\varepsilon_{t}^{g} \sim N\left(0, \sigma_{g}^{2}\right)$.

The model features eight exogenous disturbances: total factor productivity, price markup, wage mark-up, investment-specific technology, risk premium, net worth of financial intermediaries, exogenous spending, and monetary policy shocks.

SW model. The standard Smets and Wouters economy does not feature capital producers and financial intermediaries. The price of capital, equation (10), is given by

$$
q_{t}=q_{1 r} E_{t} q_{t+1}+\left(1-q_{1 r}\right) E_{t} z_{t+1}^{k}-\left(r_{t}-\pi_{t+1}\right)
$$

where $q_{1 r}=\frac{(1-\delta)}{z_{*}^{k}+(1-\delta)}$. The exogenous disturbance to net worth of financial intermediaries is clearly absent. 


\section{Estimation procedure}

We estimate the model using Bayesian methods. The loglinearized model is solved by applying the algorithm proposed by Sims (2002). As in Bayesian practice, the likelihood function, evaluated by implementing the Kalman Filter, and the prior distribution of the parameters are combined to calculate the posterior distribution. The posterior Kernel is then simulated numerically using the Metropolis-Hasting algorithm with 150,000 replications for two chains. The two DSGE models, the SWBF and the SW are estimated for the US quarterly data over the period 1984Q1-2000Q4 as in Schorfheide et al. (2010). ${ }^{2}$ To estimate the baseline SWBF model we use GDP, investment, consumption, wages, net worth of financial intermediaries, hours of work, GDP deflator inflation and the federal funds rate. We include net worth of financial intermediaries as a financial observable since the model features a net worth shock. ${ }^{3}$

The SW model is estimated using the standard seven observable variables and structural shocks.

Both models are estimated with a number of shocks equal to observable variables to avoid the stochastic singularity. The following set of measurement equations shows the link between the observable variables in the dataset and the endogenous variables of the DSGE model:

$$
\left[\begin{array}{c}
\Delta Y_{t}^{o} \\
\Delta C_{t}^{o} \\
\Delta I_{t}^{o} \\
\Delta W_{t}^{o} \\
\Delta N_{t}^{o} \\
L_{t}^{o} \\
\pi_{t}^{o} \\
r_{t}^{n, o}
\end{array}\right]=\left[\begin{array}{c}
\bar{\gamma} \\
\bar{\gamma} \\
\bar{\gamma} \\
\bar{\gamma} \\
\bar{\gamma}^{N} \\
\bar{l} \\
\bar{\pi} \\
\bar{r}^{n}
\end{array}\right]+\left[\begin{array}{c}
\hat{Y}_{t}-\hat{Y}_{t-1} \\
\hat{C}_{t}-\hat{C}_{t-1} \\
\hat{I}_{t}-\hat{I}_{t-1} \\
\hat{W}_{t}-\hat{W}_{t-1} \\
\hat{N}_{t}-\hat{N}_{t-1} \\
\hat{L}_{t} \\
\hat{\Pi}_{t} \\
\hat{R}_{t}^{n}
\end{array}\right]
$$

where $\bar{\gamma}=100(\gamma-1)$ is the common quarterly trend growth rate of GDP, consumption, investment and wages; $\bar{\gamma}^{N}=100\left(\gamma^{N}-1\right)$ is the quarterly trend growth rate of net worth of financial intermediaries, as in Gelain and Ilbas (2014); $\bar{h}$ is the steady-state hours of work; $\bar{\pi}$ is the steady-state quarterly inflation rate; and $\bar{r}^{n}$ is the steady-state quarterly nominal

\footnotetext{
${ }^{2}$ Although observations on all variables are available at least from $1973 \mathrm{Q} 2$ onward, we concentrate on this period because it is characterized by the same monetary policy regime.

${ }^{3}$ Appendix A contains a detailed discussion of data sources, definitions and transformations, while Appendix $\mathrm{B}$ investigates the robustness of results to an alternative financial variable, the credit spread.
} 


\begin{tabular}{lll}
\hline Parameter & & Value \\
\hline Capital depreciation rate & $\delta$ & 0.025 \\
Kimball aggregator in the goods market & $\eta_{p}$ & 10 \\
Kimball aggregator in the labor market & $\eta_{w}$ & 10 \\
Gross mark-up in the labor market & $\lambda_{w}$ & 1.5 \\
Government share of output & $\frac{G}{Y}$ & 0.18 \\
Survival rate of financial intermediaries & $\varpi$ & 0.9715 \\
Fraction of divertable assets & $\phi$ & 0.515 \\
Fraction of assets given to new bankers & $\xi$ & 0.001 \\
\hline
\end{tabular}

Table 1: Calibration

interest rate. $^{4}$

Our general calibration and estimation strategy follows the standard procedure proposed by Smets and Wouters (2007) adapted to the baseline model augmented with financial intermediation. In particular, we calibrate the parameters i) using a priori source of information and ii) to match some stylized facts over the period of consideration. The time period in the model corresponds to one quarter in the data. As shown in Table 1, the discount factor, $\beta$, is set equal to 0.99 , implying a quarterly steady state real interest rate of $1 \%$. The depreciation rate of capital, $\delta$, is set equal to 0.025 . The Kimball aggregators in the goods and labor market are equal to 10, and the steady state gross wage mark-up is set to 1.5. The share of government to GDP is equal to 0.18. Similarly to Villa (2015), the financial parameters $-\varpi, \phi$ and $\chi$ - are calibrated to target an average working life of bankers of almost a decade, a steady state spread of 150 basis points and a steady state leverage ratio of financial intermediaries equal to 4 .

The remaining parameters governing the dynamics of the model are estimated using Bayesian techniques. ${ }^{5}$ The locations of the prior mean correspond to those in Smets and Wouters (2007).

\section{Evaluating forecast accuracy}

The SWBF and SW models are recursively estimated from 1984Q1 to 2000Q4. The pseudo out-of-sample forecasting estimation considers two periods: from 2001Q1 to 2008Q4 (with 32

\footnotetext{
${ }^{4} \mathrm{~A}$ hat over a variable represents log-deviation from steady state.

${ }^{5}$ Dynare toolbox for Matlab is used for the computations.
} 
forecast periods in the last recursive sample) and from 2009Q1 to 2013Q4 (with 20 forecast periods in the last recursive sample). A multi-steps forecasting analysis is implemented with forecasts for the horizon $h \in(1,2,4,6,8,12)$. We assess the predictability of the two models by evaluating the point and the density forecasts. ${ }^{6}$ The point forecasting accuracy is evaluated in terms of Mean Forecast Error (MFE) and Root Mean Squared Forecast Error (RMSFE). For the density evaluation, we report the average of the log predictive density scores (LPDS) and the probability integral transform (PIT) histograms.

\subsection{Point Forecast Evaluation}

Before presenting the statistics computed on the forecast errors, Figure 1 shows the onequarter forecast series for output growth, investment growth, inflation, and federal funds rate (FFR) for the SWBF and the SW models for the whole forecasting period, which starts in 2001Q1. ${ }^{7}$ The graphical demonstration of the forecasting performance is useful to evaluate which model exhibits a better forecasting performance in the recent years, similarly to Gürkaynak et al. (2013) and Marcellino and Rychalovska (2014). Output growth sharply falls at the end of 2008; investment growth and inflation reached the minimum value in 2009, while the nominal interest rate reached the zero lower bound in 2009. With exception of the FFR, the fall of the three other variables is followed by a recovery.

The forecasts for the two DSGE models are similar, even if for output growth the SW model yields a better prediction. Overall, three main results emerge from Figure 1: first, none of the two models is able to predict the sharp contraction in output and investment occurred during the financial crisis. Second, both models produce good forecasts for the FFR and, to a minor extent, for inflation. Third, the figure suggests us that we can split the forecasting sample as follows: 2001Q1 - 2008Q4 and 2009Q1 - 2013Q4. ${ }^{8}$

\footnotetext{
${ }^{6}$ As described in Wolters (2015) and in Kolasa and Rubaszek (2015), for each parameter a large number of values are drawn from the parameter's posterior distribution. We take each 20th draw from the final 150,000 parameter draws calculated by the Metropolis-Hastings algorithm, which produces 7,500 draws from the posterior distribution. For each of them, we draw seven shock trajectories to generate the predictions for the seven macrovariables of interest. The obtained 52,500 trajectories are draws from the predictive density and hence can be used to evaluate the density forecasts. The point forecasts are calculated as means of these draws (see Wolters, 2015, for technical details).

${ }^{7}$ Since the sample ends in 2013Q4, we compute forecast errors on the basis of 52 observations for the one-quarter forecast.

${ }^{8}$ For point and density forecasts analysis, we also split the sample before and after $2007 / 2008$, considering
} 

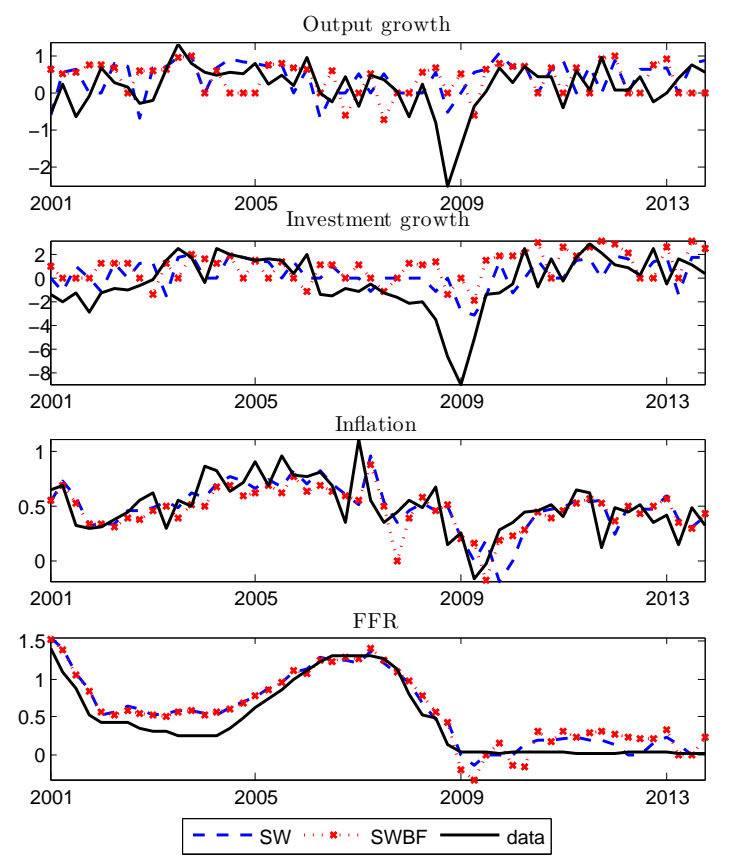

Figure 1: One quarter ahead.

Table 2 reports the Mean Forecast Error (MFE) for the period 2001Q1-2008Q4 for seven macroeconomic variables. Note that positive MFE implies that on average the model undepredicts the historical values of the series. For all horizons, both models are not biased in forecasting consumption; instead they underpredict inflation, interest rates, wage and hours. The SWBF model overpredicts output growth, while the SW model does not show a statistically significant bias. Both models overpredict investment, although on longer horizons the MFEs are not statistically different from zero and the bias is statistically significant only for the short horizons.

Table 3 reports the MFE for the period 2009-2013. Results are remarkably similar to ones shown in Table 2, especially for output growth which is still underpredicted by the SWBF model. The bias is statistically significant during this period for investment and hours.

A possible explanation for the model-based forecasts for investment can be found in the assumption of a common trend growth rate to real GDP, consumption and investment which is not in line with the data, as noted also by Kolasa and Rubaszek (2015). In fact, investment exhibits in the data a growth rate which is about $40 \%$ lower than that of output and consumption over the whole sample. Moreover, during the forecasting period 2001-2013, the financial turmoil and crisis. The results are similar and robust to changing the ending/starting date of the two samples. 


\begin{tabular}{clccccccc}
\hline & & Output & Inflation & FFR & Wage & Consumption & Investment & Hours \\
\hline Horizon & & & & & & & & \\
\multirow{2}{*}{1} & SW & 0.01 & $0.13^{* *}$ & $1.12^{* * *}$ & $0.46^{* * *}$ & $0.25^{* *}$ & $-0.80^{* *}$ & 0.37 \\
& SWBF & $-0.37^{* *}$ & $0.27^{* * *}$ & $1.11^{* * *}$ & $0.32^{* *}$ & -0.08 & $-0.92^{* *}$ & $1.74^{* * *}$ \\
\hline \multirow{2}{*}{2} & SW & -0.02 & $0.15^{* * *}$ & $0.98^{* * *}$ & $0.31^{* *}$ & 0.17 & $-0.93^{* *}$ & 0.34 \\
& SWBF & $-0.29^{* *}$ & $0.31^{* * *}$ & $0.98^{* * *}$ & $0.35^{* * *}$ & -0.02 & $-0.81^{* * *}$ & $1.52^{* * *}$ \\
\hline \multirow{2}{*}{4} & SW & -0.14 & $0.19^{* * *}$ & $0.74^{* * *}$ & $0.46^{* * *}$ & 0.22 & $-1.12^{* * *}$ & 0.21 \\
& $\mathrm{SWBF}$ & $-0.34^{* * *}$ & $0.30^{* * *}$ & $0.76^{* * *}$ & $0.28^{* *}$ & -0.06 & $-1.06^{* * *}$ & $1.12^{*}$ \\
\hline \multirow{2}{*}{6} & $\mathrm{SW}$ & 0.00 & $0.21^{* * *}$ & $0.58^{* * *}$ & $0.35^{* *}$ & 0.17 & -0.67 & 0.33 \\
& $\mathrm{SWBF}$ & $-0.43^{* * *}$ & $0.27^{* * *}$ & $0.60^{* * *}$ & $0.17^{* *}$ & -0.15 & $-1.10^{* * *}$ & 0.81 \\
\hline \multirow{2}{*}{8} & $\mathrm{SW}$ & -0.17 & $0.29^{* * *}$ & $0.46^{* * *}$ & $0.23^{*}$ & 0.00 & $-0.61^{* *}$ & 0.20 \\
& $\mathrm{SWBF}$ & $-0.37^{* * *}$ & $0.24^{* * *}$ & $0.46^{*}$ & $0.22^{* *}$ & -0.15 & -0.46 & 0.89 \\
\hline \multirow{2}{*}{12} & $\mathrm{SW}$ & -0.07 & $0.27^{* * *}$ & $0.32^{* *}$ & 0.14 & -0.10 & -0.30 & 0.46 \\
& $\mathrm{SWBF}$ & $-0.25^{*}$ & $0.24^{* * *}$ & 0.30 & 0.05 & -0.17 & -0.31 & 0.78 \\
\hline
\end{tabular}

Table 2: Mean Forecast Error for the sample 2001Q1-2008Q4. Asterisks ***,** and ${ }^{*}$ denote, respectively, the $1 \%, 5 \%$ and $10 \%$ significance levels.

the growth rate of output is $0.17 \%$, that of consumption is $0.22 \%$, while the growth rate of investment is $-0.27 \%$. As far as inflation is concerned, forecast values are lower than the actual ones. The average inflation rate is $0.62 \%$ in the period $1984-2000$ and it becomes $0.50 \%$ in the period 2001-2013. The possible reason for the bias can be found in the recursive estimates of the Calvo parameter: Figures 3 and 5 show an increasing trend, which is particularly evident in the latter forecasting period for both models. A lower probability of adjusting prices implies an inflation rate which might be too low compared to its actual value and this can affect inflation forecasts. The FFR is on average below its actual value because the model-based forecast might suggest a nominal interest rate below its lower bound and this becomes particularly relevant during the 2009-2013 period.

We continue our forecasting analysis by comparing the second moments of the forecast errors. Table 4 and Table 5 show the ratio of the RMSFE of the SWBF model relative to the SW model for the forecasting periods 2001-2008 and 2009-2013, respectively. Values greater than one denote that the SW model shows a better forecasting performance. To check the statistical significance of these ratios, we report the Diebold and Mariano (2002) test. We first look at output, inflation and FFR. At first glance, in the period 2001-2008, the SW model predicts better these three variables, while the SWBF model exhibits the best performance for output and inflation in the longer horizon. The Diebold-Mariano test shows 


\begin{tabular}{clccccccc}
\hline & & Output & Inflation & FFR & Wage & Consumption & Investment & Hours \\
\hline Horizon & & & & & & & & \\
\multirow{2}{*}{1} & SW & 0.18 & $0.37^{* * *}$ & $1.90^{* * *}$ & 0.22 & $0.32^{* *}$ & -0.32 & $7.60^{* * *}$ \\
& SWBF & 0.02 & $0.42^{* * *}$ & $1.87^{* * *}$ & $0.30^{*}$ & $0.41^{*}$ & $-1.42^{* *}$ & $8.23^{* * *}$ \\
\hline \multirow{2}{*}{2} & $\mathrm{SW}$ & 0.07 & $0.40^{* * *}$ & $1.84^{* * *}$ & $0.33^{*}$ & $0.29^{* * *}$ & -0.62 & $7.58^{* * *}$ \\
& $\mathrm{SWBF}$ & -0.05 & $0.43^{* * *}$ & $1.69^{* * *}$ & $0.34^{* *}$ & $0.43^{* *}$ & $-1.64^{* *}$ & $8.07^{* * *}$ \\
\hline \multirow{2}{*}{4} & $\mathrm{SW}$ & -0.09 & $0.45^{* * *}$ & $1.63^{* * *}$ & $0.33^{* * *}$ & $0.30^{* *}$ & -1.15 & $7.53^{* * *}$ \\
& $\mathrm{SWBF}$ & $-0.34^{* *}$ & $0.37^{* * *}$ & $1.44^{* * *}$ & 0.22 & $0.41^{* *}$ & $-3.05^{* * *}$ & $7.58^{* * *}$ \\
\hline \multirow{2}{*}{6} & $\mathrm{SW}$ & -0.09 & $0.39^{* * *}$ & $1.51^{* * *}$ & $0.39^{* *}$ & 0.08 & $-1.69^{* * *}$ & $7.35^{* * *}$ \\
& $\mathrm{SWBF}$ & $-0.51^{* * *}$ & $0.35^{* * *}$ & $1.18^{* * *}$ & 0.17 & 0.20 & $-2.94^{* * *}$ & $6.69^{* * *}$ \\
\hline \multirow{2}{*}{8} & $\mathrm{SW}$ & -0.12 & $0.45^{* * *}$ & $1.37^{* * *}$ & $0.39^{* *}$ & 0.09 & $-1.56^{* * *}$ & $6.74^{* * *}$ \\
& $\mathrm{SWBF}$ & $-0.63^{* *}$ & $0.32^{* * *}$ & $0.97^{* * *}$ & $0.30^{* *}$ & -0.02 & $-3.02^{* * *}$ & $6.11^{* * *}$ \\
\hline \multirow{2}{*}{12} & $\mathrm{SW}$ & $-0.36^{*}$ & $0.44^{* * *}$ & $1.12^{* * *}$ & 0.08 & -0.05 & $-1.48^{* * *}$ & $5.63^{* * *}$ \\
& $\mathrm{SWBF}$ & $-0.56^{* *}$ & $0.30^{* * *}$ & $0.60^{* * *}$ & 0.14 & $-0.38^{* *}$ & $-2.33^{* * *}$ & $3.37^{* * *}$ \\
\hline
\end{tabular}

Table 3: Mean Forecast Error for the sample 2009Q1-2013Q4. Asterisks ***, ** and * denote, respectively, the $1 \%, 5 \%$ and $10 \%$ significance levels.

that the forecasting accuracy of the two models is not significantly different from each other, but at horizon 8 when the SWBF model outperforms the SW model in forecasting output and inflation. RMSFE for inflation at horizons 2 and 4 and for FFR at horizon 4 are statistically significantly above unity. To rationalize these results, we first investigate the RMSFE of the other variables. On average, the SW model forecasts better consumption, investment, hours, but not the wage. Overall, adding financial frictions on the banking sector does not uniformly improve the forecasting accuracy of output and its components.

For the period 2009-2013, Table 5 shows that the SWBF model outperforms the SW model for inflation and the FFR, while the SW model dominates in forecasting output and its components. According to the Diebold-Mariano test, the forecasting performance of the two models is significantly different only at horizon 4 and 12 for output, at most horizons for the FFR and for some horizons of consumption and investment.

In order to rationalize these results, we examine the time dimension of the estimated parameters to check for possible model instabilities in the structural parameters that affect the analysis of forecasting. In particular, both models are recursively estimated with the first window covering the period 1984Q1-2000Q4 and the last window covering the whole estimation sample, 1984Q1-2013Q4. This procedure yields 53 different posterior densities of all parameters, each of which is computed with the Metropolis-Hasting algorithm with two 


\begin{tabular}{clllllll}
\hline & Output & Inflation & FFR & Wage & Consumption & Investment & Hours \\
\hline Horizon & & & & & & & \\
1 & 1.60 & 1.31 & 0.99 & 0.92 & 1.27 & 1.01 & 1.04 \\
2 & 1.13 & $1.41^{* *}$ & 1.01 & 0.85 & 1.13 & 0.89 & 1.01 \\
4 & 1.43 & $1.33^{*}$ & $1.05^{*}$ & 0.84 & 0.92 & $1.04^{* * *}$ & 1.13 \\
6 & $1.15^{*}$ & 1.20 & 1.07 & 0.72 & 1.04 & $0.94^{*}$ & 1.08 \\
8 & $0.98^{* * *}$ & $0.83^{* * *}$ & 1.07 & 0.90 & $1.02^{*}$ & 1.12 & 1.36 \\
12 & 0.96 & $0.89^{*}$ & 1.04 & 1.04 & $1.06^{* * *}$ & 0.99 & 1.62 \\
\hline
\end{tabular}

Table 4: Root Mean Square Forecast Error. All RMSFE are computed as a ratio to the RMSFE in the SW model. Forecasting evaluation period: 2001Q1-2008Q4 . Asterisks ***, ** and * denote, respectively, the 1\%, $5 \%$ and $10 \%$ significance levels of the Diebold-Mariano test, where the long-run variance is calculated with the Newey-West method.

\begin{tabular}{clllllll}
\hline & Output & Inflation & FFR & Wage & Consumption & Investment & Hours \\
\hline 1 & 1.44 & 1.01 & 0.99 & 1.19 & 1.12 & 1.08 & 1.10 \\
2 & 1.41 & 0.99 & $0.93^{* * *}$ & 0.93 & 1.37 & 1.38 & 1.08 \\
4 & $1.09^{* * *}$ & 0.80 & $0.89^{*}$ & 0.83 & $1.07^{* * *}$ & $1.73^{* *}$ & $1.02^{* * *}$ \\
6 & 1.50 & 0.87 & $0.79^{* * *}$ & $0.82^{*}$ & $1.37^{*}$ & 1.54 & $0.94^{* * *}$ \\
8 & 1.15 & 0.74 & $0.71^{* * *}$ & 0.92 & $1.08^{*}$ & 1.54 & $0.94^{* * *}$ \\
12 & $1.29^{* * *}$ & 0.72 & $0.59^{* *}$ & 1.31 & 0.92 & 1.31 & $0.75^{* * *}$ \\
\hline
\end{tabular}

Table 5: Root Mean Square Forecast Error. All RMSFE are computed as a ratio to the RMSFE in the SW model. Forecasting evaluation period: 2009Q1-2013Q4. Asterisks ***, ** and * denote, respectively, the $1 \%, 5 \%$ and $10 \%$ significance levels of the Diebold-Mariano test, where the long-run variance is calculated with the Newey-West method. 
chains of 150,000 draws each.

The literature offers at least three different approaches to deal with the issue of parameters instability. The first features time-varying coefficients/ stochastic volatilities (e.g. FernándezVillaverde et al., 2010; Caldara et al., 2012; Bekiros and Paccagnini, 2013). Second, Eo (2009), Bianchi (2013) and Foerster et al. (2014), among others, propose Markov-switching DSGE modeling. Third, Castelnuovo (2012) and Hurtado (2014) present a rolling-window estimation in order to investigate possible instabilities in the structural parameters of a medium scale model.

In our empirical contribution, we recursively estimate the DSGE model and we can adapt the idea of the rolling-window estimation to check for possible instabilities. Moreover, as stated in Castelnuovo (2012), this methodology does not force the data to "discretize" the economy which actually occurs in the regime-switching approach.

Our chosen methodology has at least two caveats. First, the DSGE models do not feature a zero lower bound (ZLB) constraint on the nominal interest rate, which is instead present in the data. Hirose and Inoue (2014) investigate how and to what extent parameter estimates can be biased in DSGE models lacking this constraint. They find that when the nominal interest rate is bounded at zero for $6.4 \%$ of quarters the bias is small, while it becomes large when the probability of hitting the ZLB increases. Given our estimation sample, estimates up to 2010Q3 feature $6.5 \%$ of quarters in which the ZLB hits the economy. Hence, according to the study of Hirose and Inoue (2014) the bias should not be significant. However, it is worth noting that the bias in parameter estimates could potentially increase afterward. Second, since estimation samples differ in their window size, the precision of estimates could be affected. We plan to use alternative techniques for parameters instability in DSGE models with banking in future research.

Figures 2 and 3 show the evolution of the shock processes and of parameters of the SW model. While the standard deviations and the AR parameters of the government spending, monetary policy and price mark-up shocks are pretty constant over the recursive sample, other shocks show a considerable degree of instability. The risk premium shock, in particular, shows a possible regime change. Its volatility drops by more than a half after 2009, while its 
persistence more than doubles. In the Smets and Wouters (2007) model the risk premium shock captures the wedge between different interest rates. We can consider two measures as proxies for spreads: (i) Moody's BAA corporate bond yield minus ten-year Treasury constant maturity rate, as in Del Negro and Schorfheide (2013); and (ii) the difference between the 3 -month bank prime loan rate and the quarterly Treasury bill rate. ${ }^{9}$ In the data spreads skyrocketed in 2008 and then fall quite sharply afterward. For both measures of the spreads, their volatilities are lower in the sample 2009Q1-2013Q4 compared to the sample 2001Q12008Q4. The volatility of the bank spread, in particular, decreased by more than $75 \%$ in the more recent sample. The higher persistence of risk premium shock can play a role in explaining the slow recovery from the financial crisis (e.g. Huang et al., 2014). The higher volatilities of the investment-specific technology, TFP and wage mark-up shocks in the period 2009-2013 are likely to capture the higher volatilities of the investment and wage series.

This is also in line with the lower estimated investment adjustment costs parameter shown in Figure 3. This figure shows recursive estimates of the most relevant parameters. ${ }^{10} \mathrm{~A}$ regime change is particularly evident for the parameter measuring price stickiness, which has risen in the recent recursive sample. Calvo parameters for price and wage stickiness show considerable variations in the time-varying literature, such as in the study of Giraitis et al. (2014) who also find that the Calvo parameter for prices increased sharply in 2010. The coefficient of relative risk aversion decreased by more than 50\% since 2009. Hence, the willingness of households to substitute consumption over different periods has decreased after the financial crisis, which seems to be a puzzling result. This parameter shows a pattern similar to the risk shock. The reduction in the volatility of the latter makes households more willing to substitute consumption over time.

The Taylor rule has become more inertial over time and its responsiveness to inflation is pretty constant over the recursive sample. The chart showing the responsiveness to the output gap is remarkably similar to the model-implied output gap, which considerably falls from 2009 onwards.

\footnotetext{
${ }^{9}$ This is the financial observable used in the robustness exercises presented in Appendix B.

${ }^{10}$ In the interest of brevity, we do not report charts on the recursive estimates of all parameters, which are available upon request.
} 

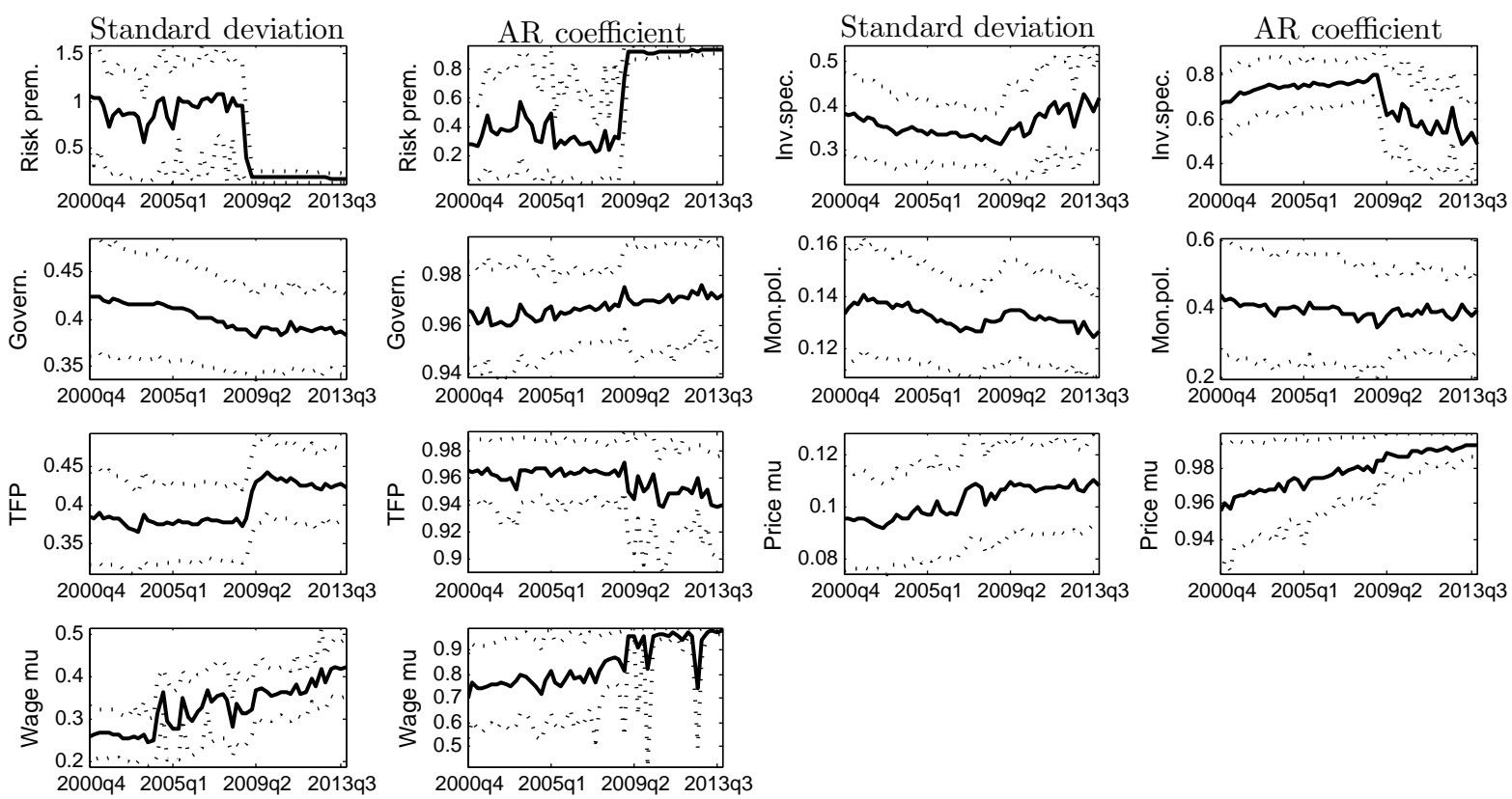

Figure 2: Evolution of the shock processes of the SW model. Solid lines represent the posterior mean, while dotted lines 5th and 95th posterior percentiles. Estimates are computed based on the recursive estimation sample starting from 1984Q1-2000Q4 and ending in 2013Q4.

In the SWBF model the regime change in the estimation of shocks and parameters is less evident compared to that of the SW model, as shown by Figures 4 and 5 . This can be explained by the richer set of structural shocks and observable variables in the former model. The risk premium shock seems to capture the volatility due to the dot-com bubble, while the volatility of the net worth shock drops from 2009 onwards. It is worth noting that the growth rate of net worth is more volatile in the period 2001Q1-2008Q4 than in the recent period. The volatilities of the TFP, price mark-up and wage mark-up, instead, increased in 2009-2013. As far as the parameters are concerned, the regime change is evident mainly for the interest-rate responsiveness to the output gap, whose chart is similar to the model-implied output gap, as in the SW model.

It is interesting to investigate whether there are significant differences in the estimated values of shocks and parameters across the two models. The most different shock is the risk premium, whose volatility is much higher in the SW model, particularly during the period 2003-2009. The inclusion of the net worth shock in the SWBF model captures some of the volatility of the risk premium shock. Three main parameters vary across the models: the 

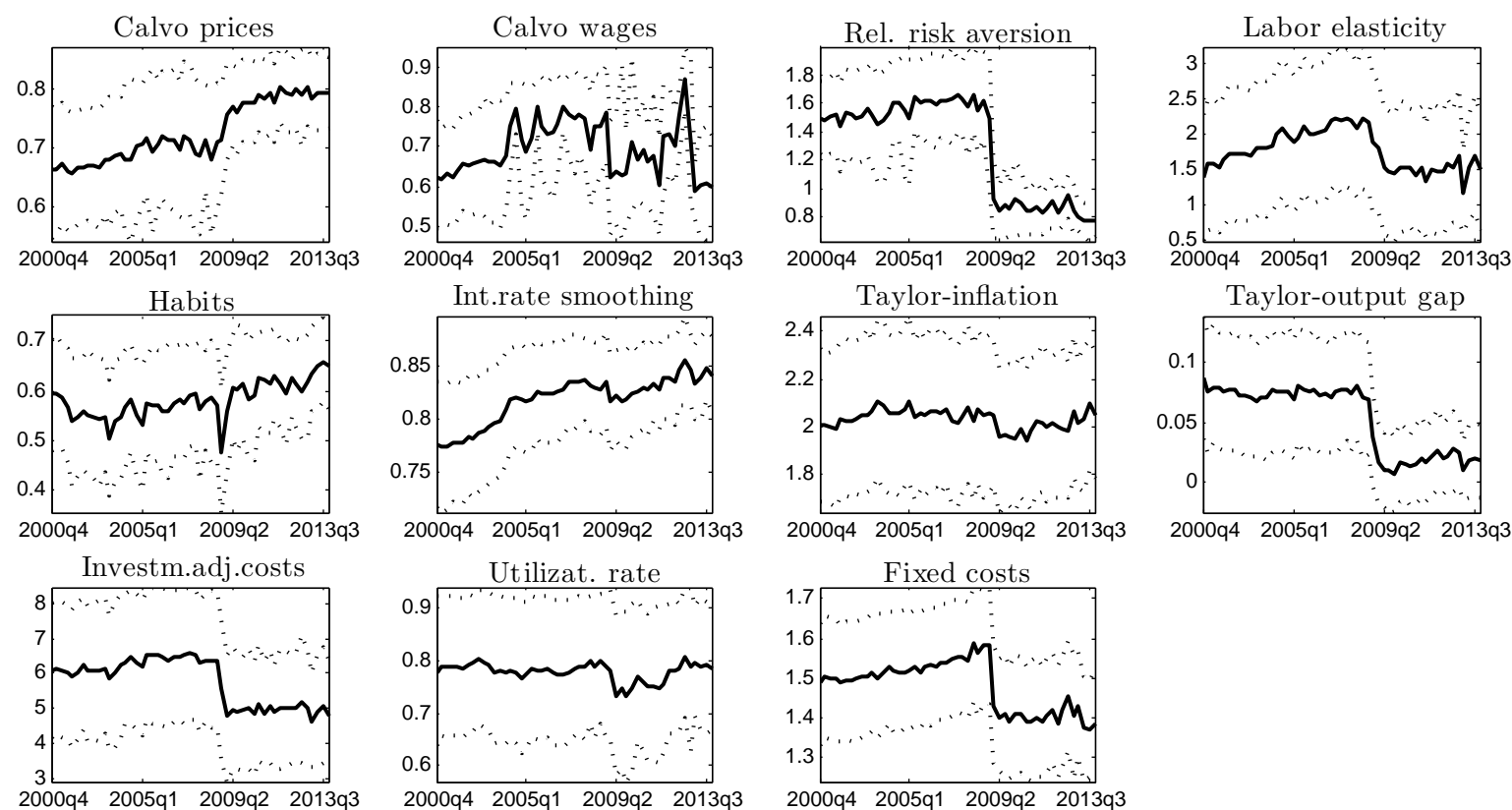

Figure 3: Evolution of the parameters of the SW model. Solid lines represent the posterior mean, while dotted lines 5th and 95th posterior percentiles. Estimates are computed based on the recursive estimation sample starting from 1984Q1-2000Q4 and ending in 2013Q4.

relative risk aversion, habits in consumption and investment adjustment costs. The former parameter sharply fell in the period 2009-2013 in the SW model, while it shows an opposite trend in the SWBF model.

According to Bommier et al. (2012), risk aversion also reflects the households' willingness to marginally reduce risks and precautionary saving increases with risk aversion. The SWBF model might capture the higher perceived risk in period following the collapse of Lehman Brothers. Habits in consumption are lower in the model featuring the banking sector. De Graeve (2008) presents an empirical comparison between the SW model and the model by Bernanke et al. (1999). He finds that point estimates of the risk aversion and habit parameter for the period 1954-2004 are respectively higher and lower in the model featuring financial frictions. De Graeve argues the inclusion of financial frictions generates sufficient internal propagation to account for persistence in consumption, without the need to rely on the "conventional" estimates of habits. However, the results of the RMSFE show that the SW model provides, on average, better forecasts for consumption. Hence a higher degree of habit in consumption seems to be desirable from a forecasting viewpoint. Similarly to Kolasa 

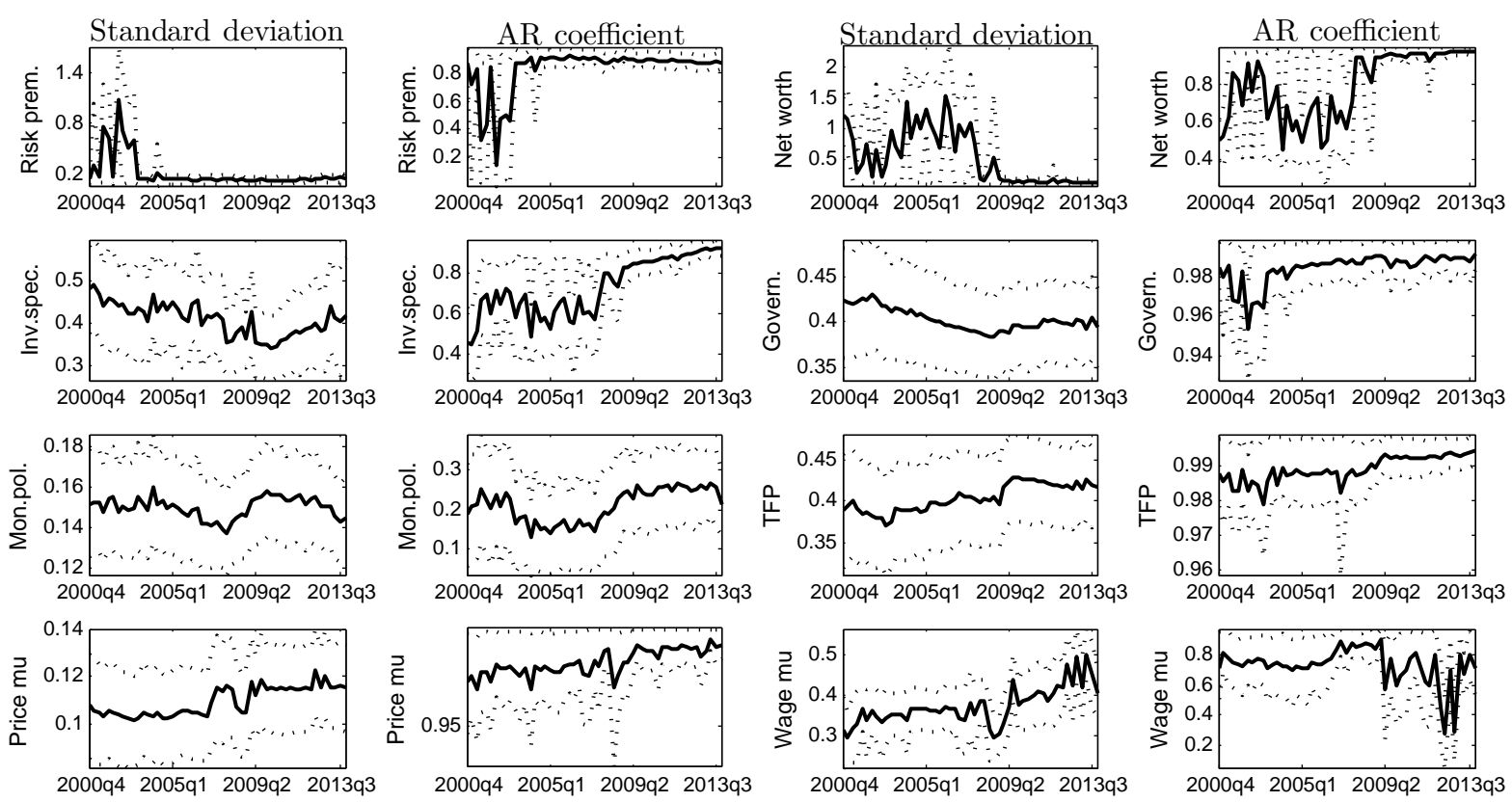

Figure 4: Evolution of the shock processes of the SWBF model, where the observable financial variable is net worth. Solid lines represent the posterior mean, while dotted lines 5th and 95th posterior percentiles. Estimates are computed based on the recursive estimation sample starting from 1984Q1-2000Q4 and ending in 2013Q4.

and Rubaszek (2015), investment adjustment costs are smaller in the SWBF model compared to those in the SW model. The same rationale applies: the internal propagation mechanism of the SWBF generates enough persistence in investment without relying on high estimates of the investment adjustment costs.

The variation in the estimation of shocks and parameters implies that the role of shocks in affecting macroeconomic variables is changing over time and across models' specification. Figure 6 shows the evolution of the variance decomposition implied by the estimated SW model. The government and monetary policy shocks play an important role in affecting movements in output. The role of the risk premium shock increased following the collapse of Lehman Brothers, while the contrary happens for the investment-specific technology shock. The explanatory power of the supply shocks is lower than all the demand shocks. Inflation is mainly driven by supply shock, with risk premium shocks accounting for about $40 \%$ of its fluctuations at the end of the recursive sample. The fed funds rate is mainly explained by the investment-specific technology shock. 

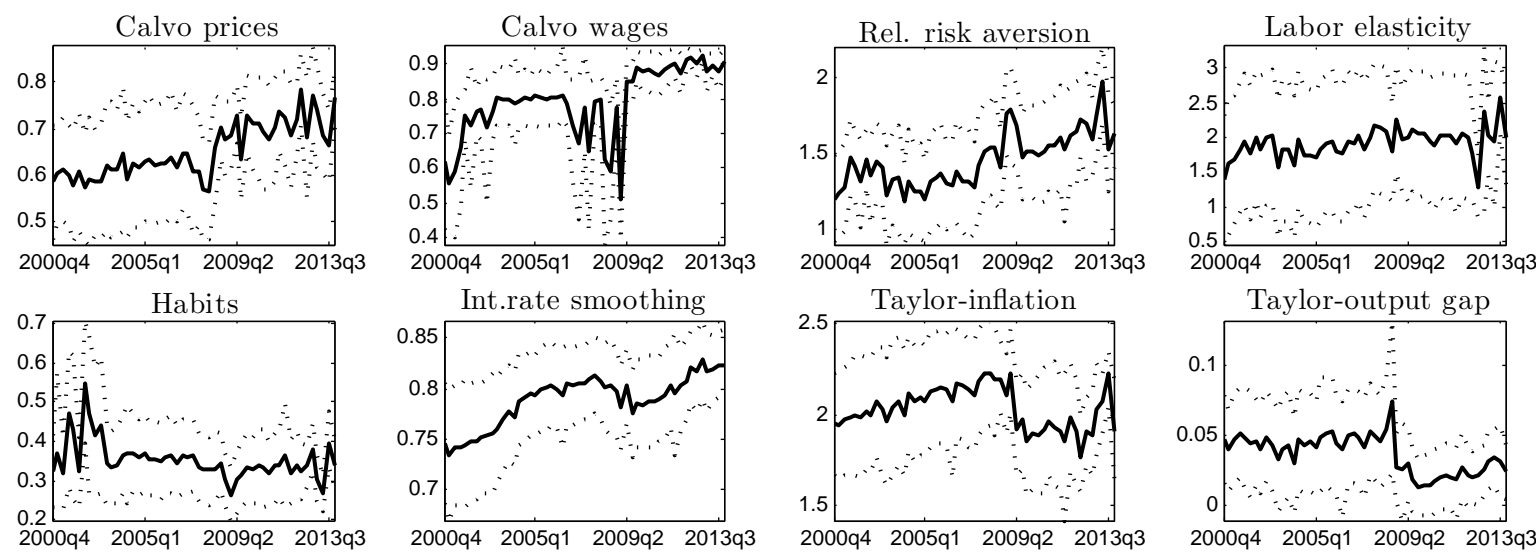

$2000 q 4 \quad 2005 q 1 \quad 2009 q 2 \quad 2013 q 3$
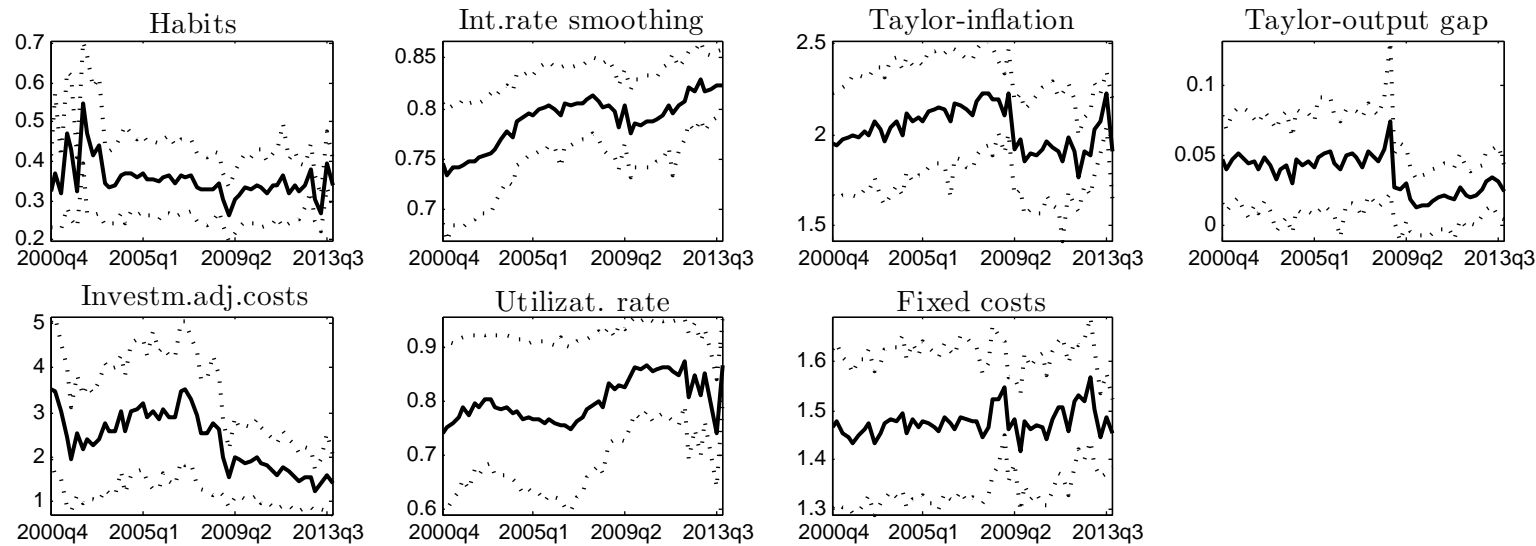

Figure 5: Evolution of the parameters of the SWBF model, where the observable financial variable is net worth. Solid lines represent the posterior mean, while dotted lines 5th and 95th posterior percentiles. Estimates are computed based on the recursive estimation sample starting from 1984Q1-2000Q4 and ending in 2013Q4.

The risk premium shock experiences three phases in accounting for movements in the interest rate: first, a limited role up to 2008. Second, in the recursive sample 2009-2012Q2 it explains about $40 \%$ of movements in the nominal interest rate. In the latest recursive sample it becomes its most important driver.

Figure 7 shows the recursive variance decomposition of the SWBF model, which features also a net worth shock. Supply shocks are the dominant factors behind movements in output. The most important demand shocks are government and monetary policy, with an increasing role of net worth shocks at the end of the recursive sample. The SWBF model features a financial accelerator mechanism through banks' balance sheet: a contractionary shock is generally associated with a rise in the credit spread and a contraction in the quantity of credit. This in turn diminishes the productive capacity of the economy. Reifschneider et al. (2013) argue that in the recent financial crisis a significant portion of the damage to the supply side of the economy plausibly was endogenous to the weakness in aggregate demand. The different role of supply and demand shocks in the SW and SWBF models can be explained by 

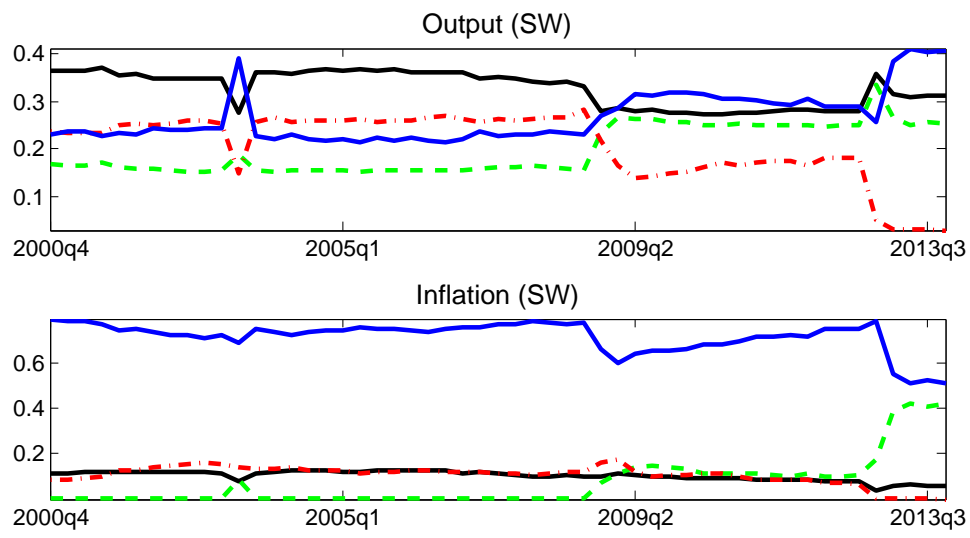

FFR $(S W)$

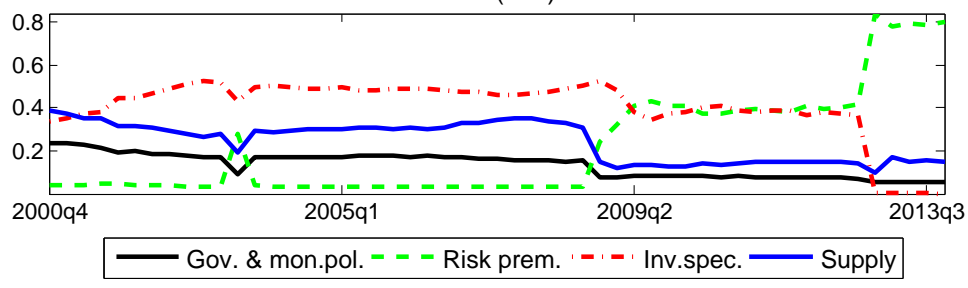

Figure 6: Evolution of the variance decomposition of the SW model. The black line represents government and monetary policy shocks, the blue line the TFP, price mark-up and wage markup shocks while NW stands for net worth. Estimates are computed based on the recursive estimation sample starting from 1984Q1-2000Q4 and ending in 2013Q4.

the reduced amount of credit that contracted production in the latter model. Supply shocks are the most important drivers of inflation, with a bigger role in the latest sample compared to the SW model. It is well known that supply shocks play a major role in accounting for the variance of inflation (e.g. Smets and Wouters, 2007); its larger role in the SWBF model can provide some intuition on the better forecasting performance of this model as far as inflation is concerned. The net worth shock is a dominant factor behind movements in the fed funds rate. This helps in explaining the better forecasts of the SWBF model for this variable. Finally, it is worth noting that the lower degree of instability of shocks and parameters in the SWBF model leads to a more stable profile of the recursive variance decomposition analysis in the SWBF model, compared to that in the SW model. 

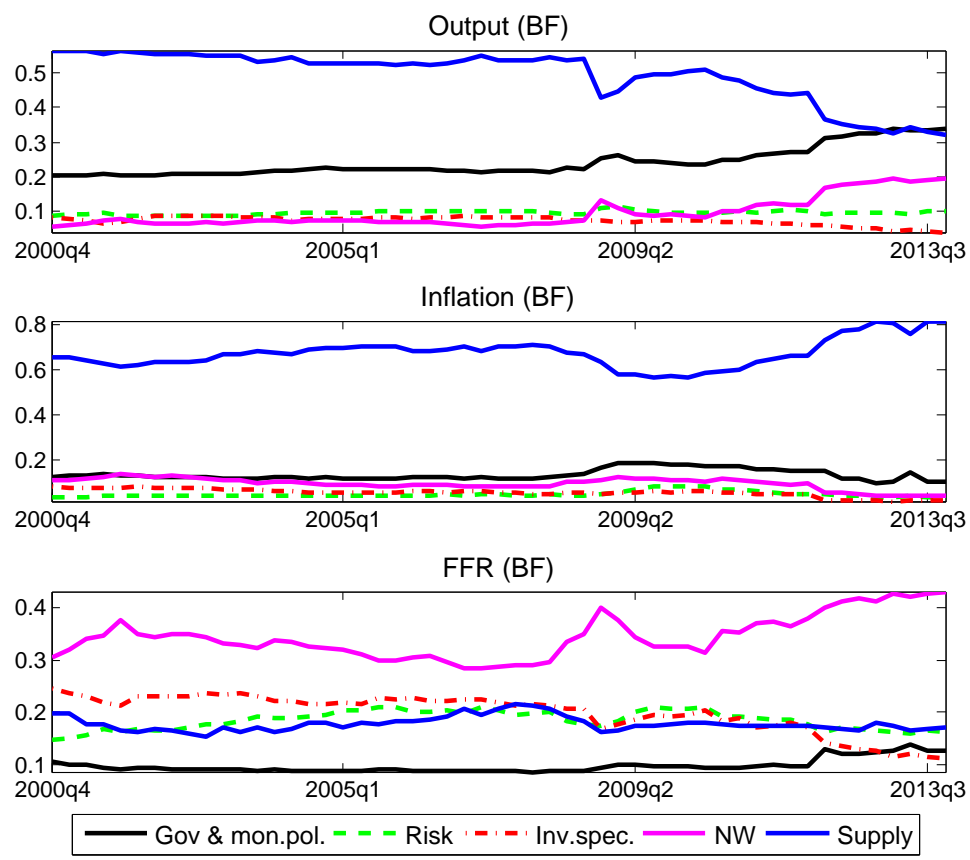

Figure 7: Evolution of the shock variance decomposition of the SWBF model. The black line represents government and monetary policy shocks, the blue line the TFP, price mark-up and wage mark-up shocks. Estimates are computed based on the recursive estimation sample starting from 1984Q1-2000Q4 and ending in 2013Q4.
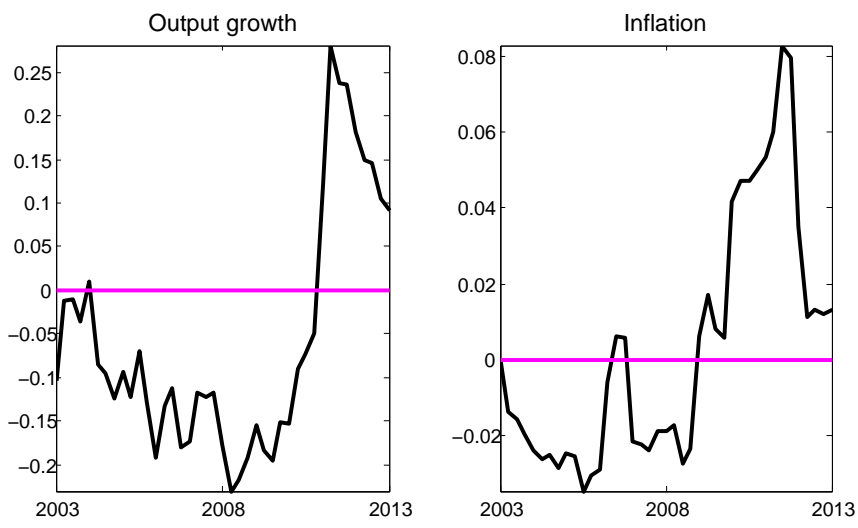

Figure 8: Difference over time in 1-quarter-ahead rolling RMSFEs between the SW and SWBF models for output growth and inflation. At each point in time, the RMSFEs are computed using the previous 12 quarters.

This exercise has shown that the time variation of the parameters is crucial in our empirical analysis. For this reason, we plot the rolling RMSFE over time, following the same approach proposed by Del Negro and Schorfheide (2013). Figure 8 shows the difference between the RMSFE of the SW model and that of the SWBF model for one step-ahead forecasts. Hence, 
values greater than zero implies that the SWBF model yields a lower error. Both models are recursively estimated over the period 1984Q1 to 2000Q4, the out-of-sample evaluation is from 2001Q1 to 2013Q4. For each observation, the RMSFEs are computed using the 12 previous quarters (the rolling window).

Figure 8 shows that the ranking between the two models changes over time. For output growth, on average the SW is better, but there are some periods around 2010 until the end of the sample when the SWBF outperforms the other model. For inflation, on average the best model is the one with the banking sector, even if there are periods where the SW model has the best prediction ability. We can conclude that it is impossible to rank the two models ignoring the time variation, which is a relevant dimension for the forecasting analysis.

\subsection{Density Forecast Evaluation}

The forecast evaluation is completed with an assessment of the density forecasts to provide a realistic pattern of the actual uncertainty. This kind of analysis has recently become popular in forecasting exercises involving DSGE-based models (Herbst and Schorfheide, 2012; Kolasa et al., 2012; Del Negro and Schorfheide, 2013; Wolters, 2015). However, the evaluation of the density forecasts is less straightforward than the evaluation and the comparison of RMSFEs. As discussed in Wolters (2015), the true density is never observed. Notwithstanding this, the researcher can compare the distribution of observed data with density forecasts to investigate whether forecasts explain the actual uncertainty.

We evaluate and rank the density forecasts using the log predictive density scores (LPDS), similarly to Adolfson et al. (2007), Christoffel et al. (2010), Marcellino and Rychalovska (2014), among others.

Considering the assumption that $h$-step-ahead predictive density is normally distributed, the LPDS for variable $i$ can be written as:

$$
s_{t}\left(y_{t+h}^{i}\right)=-0.5\left[\log (2 \pi)+\log \left(V_{t+h / t}^{i}\right)+\left(y_{t+h}^{i}-\bar{y}_{t+h / t}^{i}\right)^{2} / V_{t+h / t}^{i}\right]
$$

where $\bar{y}_{t+h / t}^{i}$ and $V_{t+h / t}^{i}$ are the posterior mean and variance of $h$-step-ahead simulated forecast distribution for the variable $i$. 
The average score (AS) in forecasting variable $i$ with the model $m$ is given by:

$$
A S_{i, h}^{m}=\frac{1}{T_{h}} \sum_{t=T}^{T+T_{h}-1} s_{t}\left(y_{t+h}^{i}\right),
$$

where $T_{h}$ represents the number of $h$-step-ahead forecasts. As discussed in Adolfson et al. (2007), the predictive density of the DSGE models estimated using Bayesian techniques does not have a known analytical form. Hence, we approximate the DSGE predictive density using a multivariate normal density. However, this assumption depends on the property of normality for the distribution of any subset of observed variables. In Bayesian estimation of DSGE models, the parameter uncertainty is the only source of non-normality of the predictive density, as argued by Christoffel et al. (2010). In general, only a small fraction of the forecast error variance is given by parameter uncertainty, then the normality assumption does not represent a significant misspecification problem in computing the log predictive score.

Tables 6 and 7 present the score of the SWBF relative to SW for the two periods, 20012008 and 2009-2013. A positive number indicates an improvement over the SW model. Table 6 shows that for output growth, the SWBF model offers only a small improvement (less than 10\%) for horizons 2, 4, and 6. For the other horizons, instead, the SW model is marginally better, with an improvement of around 5\%. Similar mixed pattern can be detected also for consumption and wage. At the 8 and 12 quarter horizon, the SW model outperforms the SWBF model, while for shorter horizons the contrary happens with a maximum improvement of the SWBF model at horizon 4, equal to $40 \%$ over the SW log score. For inflation, FFR, and hours, the SWBF produces the best performance. Table 7 shows the LPDS in the period 2009-2013. For output growth the SW model clearly outperforms the SWBF model at any horizon. This result is in line with the findings of the point forecast reported in Table 5. An explanation for this is that the log scores of the main components of output, i.e. consumption and investment, are better in the SW model. For inflation, FFR, and hours, the SWBF is still the best model. This analysis also confirms the point density forecast in favor of the SWBF for inflation and FFR. No clear pattern emerges for wage.

In addition, we report a graphical representation of the Probability Integral Transform 
(PIT) using histograms. The PITs were developed by Rosenblatt (1952), Dawid (1984), Kling and Bessler (1989), and introduced in an economic application by Diebold et al. (1998). We can define the PIT as the transformation:

$$
p_{\tau}=\int_{-\infty}^{x_{\tau}} f(u) d u
$$

where $f(u)$ is the ex ante forecast density and $x_{\tau}$ is the ex post observed data. If the density forecast is well calibrated, $p_{\tau}$ should be independently and uniformly distributed on the uniform interval $(0,1)$ as noted by Dawid (1984), Diebold et al. (1998) and Diebold et al. (1999). Moreover, at the one step ahead horizon, PITs are independently distributed, while independence may be violated at longer horizons since multi-step-ahead forecast errors are serially correlated (see Knüppel, 2015, for more details). As described in Diebold et al. (1998), there are several graphical approaches to forecast evaluation. The most common approach is to present a visual assessment of the distribution of realized data points on the sequence of PITs represented as a histogram (as shown by Kolasa et al., 2012 and Wolters 2015, among others). Hence, the unit interval is divided in $K$ subintervals and the fraction of PITs in each of them is close to $K^{-1}$. We follow this methodology in Figures 9-12 and we set a histogram of 10 probability bands each covering $10 \%$, i.e. $K=10$. The horizontal line is expressed in percentage from 0 to 100 (where 100 means 1 in the uniform distribution). ${ }^{11}$ Bars represent the fraction of realized observations falling into deciles of density forecasts. The theoretical value of $10 \%$ for a well-calibrated model is represented by a solid line.

We compare the two models for the GDP and inflation for horizon 1. If we consider the whole period 2001-2013, the two models are better calibrated than splitting the sample. Especially, during the period 2009-2013, we recognize an empirical distribution different from the underline uniform, Figures 11 and 12. According to Kolasa et al. (2012), the DSGE models impose tight restrictions on the data, hence its misspecification should be absorbed by stochastic shocks (see Gerard and Nimark, 2008, and Del Negro and Schorfheide, 2009). Most probably, during a short sample, such as 2009-2013, the DSGE model restrictions fail

\footnotetext{
${ }^{11}$ We draw the histogram of PITs following the setup proposed by Kolasa et al. (2012). Their codes are available at: http://jmcb.osu.edu/volume-44-2012.
} 


\begin{tabular}{clllllll}
\hline & Output & Inflation & FFR & Wage & Consumption & Investment & Hours \\
\hline 1 & -4.35 & 1.23 & 5.43 & 5.96 & -12.83 & 26.42 & 57.49 \\
2 & 7.87 & 0.06 & 6.73 & 5.56 & 1.13 & 10.86 & 82.04 \\
4 & 4.16 & 1.24 & 3.66 & -5.05 & -9.05 & 41.71 & 72.04 \\
6 & 8.19 & 2.77 & 9.33 & 0.30 & -9.36 & 15.58 & 69.43 \\
8 & -2.32 & 2.39 & 5.17 & -2.33 & -10.73 & -38.28 & 58.12 \\
12 & -5.82 & 6.51 & 11.37 & 1.26 & 0.18 & -24.92 & 20.32 \\
\hline
\end{tabular}

Table 6: Percentage improvement in the log predictive scores for the period 2001Q1-2008Q4 over the SW model.

\begin{tabular}{clllllll}
\hline & Output & Inflation & FFR & Wage & Consumption & Investment & Hours \\
\hline 1 & -52.60 & 5.98 & 3.36 & -28.28 & -47.71 & -349.77 & 111.37 \\
2 & -37.62 & 4.75 & 3.62 & -14.98 & -53.87 & -233.19 & 114.42 \\
4 & -30.59 & 6.23 & 12.56 & 2.87 & -84.37 & 2.79 & 151.10 \\
6 & -19.13 & 1.21 & 15.67 & -0.89 & -85.17 & 5.50 & 103.25 \\
8 & -42.24 & -0.25 & 5.07 & 4.78 & -71.62 & -152.85 & 140.36 \\
12 & -58.61 & 1.06 & 24.88 & 2.14 & -69.50 & -88.87 & 293.22 \\
\hline
\end{tabular}

Table 7: Percentage improvement in the log predictive scores for the period 2009Q1-2013Q4 over the SW model.

to match the data. For the output growth forecasts, a large fraction of PITs falls into the 0.4-0.6 bin and the peak in the middle of the histograms of the output growth forecasts shows an overestimation of uncertainty. This result is similar to the ones reported in Del Negro and Schorfheide (2013), Kolasa et al. (2012) and Wolters (2015) and it indicates that the predictive distribution is too diffuse (Del Negro and Schorfheide, 2013). ${ }^{12}$
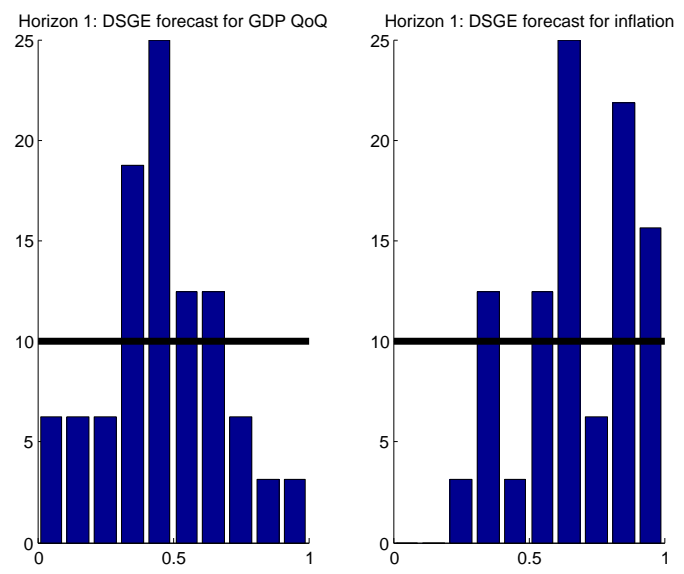

Figure 9: DSGE SW Density Forecasts: PIT Histograms for One-Quarter-Ahead Forecasts for the period 2001-2013.

\footnotetext{
${ }^{12}$ There are formal tests to check for a uniform distribution (Berkowitz, 2001). However, the results have to be treated with high caution (see Gerard and Nimark, 2008). Since the histograms have already shown a clear evidence against a uniform distribution of PITs, we do not add formal tests in our empirical analysis.
} 

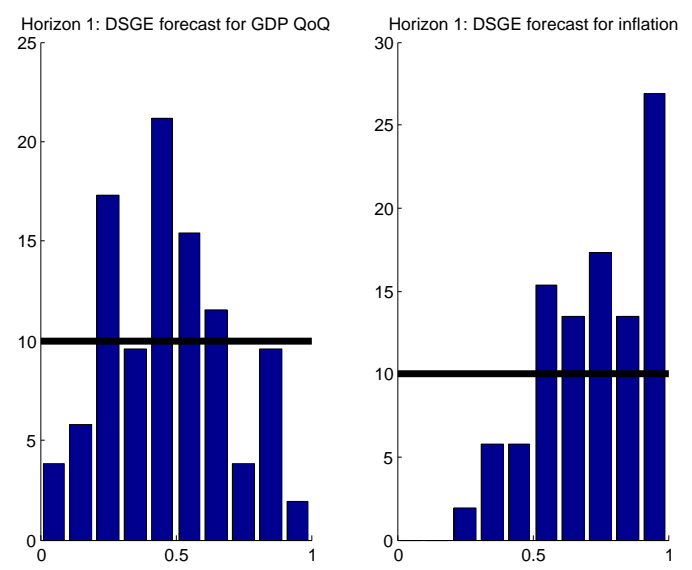

Figure 10: DSGE SWBF Density Forecasts: PIT Histograms for One-Quarter-Ahead Forecasts for the period 2001-2013.
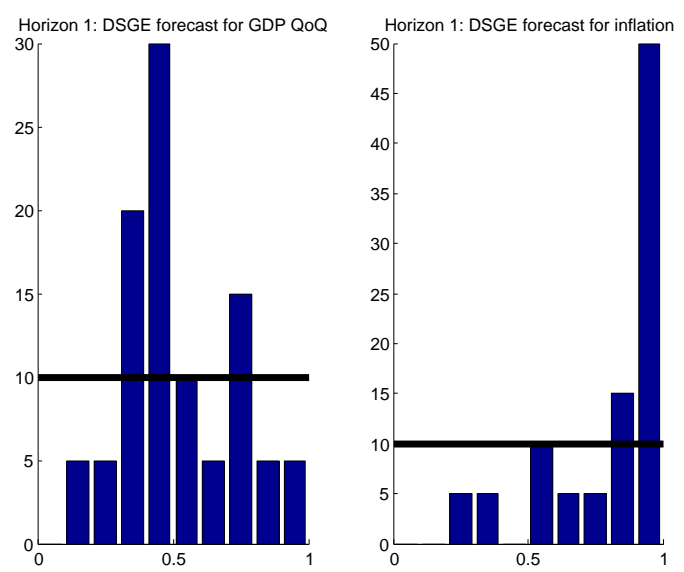

Figure 11: DSGE SW Density Forecasts: PIT Histograms for One-Quarter-Ahead Forecasts for the period 2009-2013.
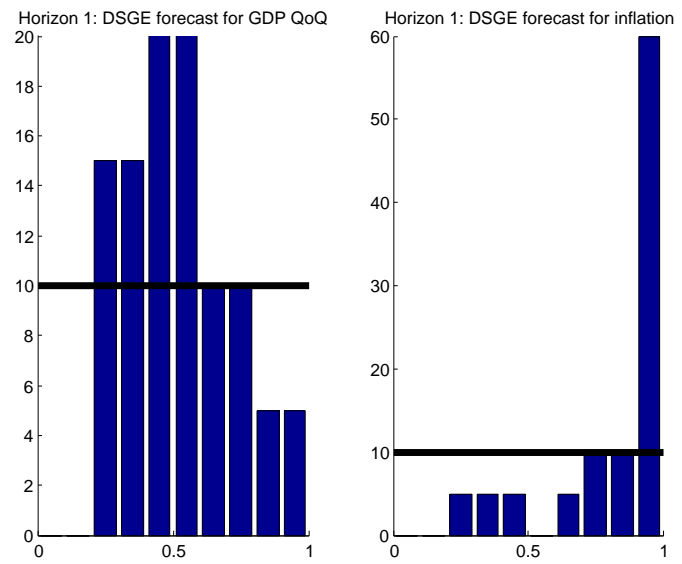

Figure 12: DSGE SW Density Forecasts: PIT Histograms for One-Quarter-Ahead Forecasts for the period 2009-2013. 


\section{Conclusion}

The Great Recession made it evident that credit market conditions play an important role in affecting business cycle fluctuations. This paper evaluates the forecasting performance of a dynamic stochastic general equilibrium (DSGE) model featuring a banking sector versus a standard DSGE model à la Smets and Wouters (2007) for the US economy. Our empirical analysis is based on a forecasting horse-race between the two models (SWBF and SW), evaluated along point and density forecast analysis. Point forecast analysis shows that in the sample 2001-2008 the SWBF model exhibits the best performance for output growth and inflation only in the longer horizon, while in the sample 2009-2013 the SWBF outperforms the SW models in forecasting inflation and the short term interest rates, but not output growth. Hence, there is no clear evidence of an outperformed model in terms of forecasting accuracy. To rationalize these results, we investigate the time dimension of the estimated parameters, based on a recursive-window estimation.

We find a regime change in the estimated parameters/shocks of the SW model, while the change is less evident in the SWBF model due to its richer modelling structure. The variation in the estimation of shocks and parameters implies that the role of shocks in affecting macroeconomic variables is also changing over time and across models' specification. A comparison of the rolling root mean square forecast error indeed reveals that the empirical ranking among models changes over time. In particular, adding a banking sector helps improving the forecasting performance of output growth and inflation in the most recent period. Density forecast analysis confirms the results of the point forecast.

This exercise turns out to be useful also for policy-making since there might be frictions which are more important in some episodes. This would lead eventually to the appropriate design of policy instruments alleviating the severity of the financial frictions. 


\section{References}

Adolfson, M., Lindé, J., and Villani, M. (2007). Forecasting performance of an open economy DSGE model. Econometric Reviews, 26(2-4):289-328.

Bekiros, S. and Paccagnini, A. (2013). On the predictability of time-varying VAR and DSGE models. Empirical Economics, 45(1):635-664.

Berkowitz, J. (2001). Testing density forecasts, with application to risk management. Journal of Business and Economic Statistics, 19(4):465-474.

Bernanke, B., Gertler, M., and Gilchrist, S. (1999). The financial accelerator in a quantitative business cycle model. Handbook of Macroeconomics, 1:1341-1393.

Bianchi, F. (2013). Regime switches, agents' beliefs, and post-world war II US macroeconomic dynamics. The Review of Economic Studies, 80(2):463-490.

Bommier, A., Chassagnon, A., and Le Grand, F. (2012). Comparative risk aversion: a formal approach with applications to saving behavior. Journal of Economic Theory, 147(4):16141641.

Brunnermeier, M., Eisenbach, T., and Sannikov, Y. (2013). Macroeconomics with financial frictions: A survey. In Acemoglu, D., Arellano, M., and Dekel, E., editors, Advances in Economics and Econometrics, Tenth World Congress of the Econometric Society. Cambridge University Press.

Caldara, D., Fernández-Villaverde, J., Rubio-Ramírez, J. F., and Yao, W. (2012). Computing DSGE models with recursive preferences and stochastic volatility. Review of Economic Dynamics, 15(2):188-206.

Calvo, G. (1983). Staggered prices in a utility-maximizing framework. Journal of Monetary Economics, 12(3):383-398.

Castelnuovo, E. (2012). Fitting U.S. Trend Inflation: A Rolling-Window Approach. In Balke, N., Canova, F., Milani, F., and Wynne, M., editors, Advances in Econometrics: DSGE 
Models in Macroeconomics - Estimation, Evaluation, and New Developments, pages 201252.

Christiano, L., Eichenbaum, M., and Evans, C. (2005). Nominal rigidities and the dynamic effects of a shock to monetary policy. Journal of Political Economy, 113(1):1-45.

Christoffel, K., Warne, A., and Coenen, G. (2010). Forecasting with DSGE models. ECB Working Paper Series, 1185.

Ciccarelli, M., Maddaloni, A., and Peydro, J. (2010). Trusting the bankers: a new look at the credit channel of monetary policy. ECB Working Paper, 1228.

Cole, H. (2011). Discussion of Gertler and Karadi: A model of unconventional monetary policy. Journal of Monetary Economics, 58(1):35-38.

Dawid, A. P. (1984). Present position and potential developments: Some personal views: Statistical theory: The prequential approach. Journal of the Royal Statistical Society, Series A, 147(2):278-292.

De Graeve, F. (2008). The external finance premium and the macroeconomy: US post-WWII evidence. Journal of Economic Dynamics and Control, 32(11):3415-3440.

Del Negro, M. and Schorfheide, F. (2009). Monetary policy analysis with potentially misspecified models. American Economic Review, 99(4):1415-1450.

Del Negro, M. and Schorfheide, F. (2013). DSGE model-based forecasting. Handbook of Economic Forecasting, 2.

Diebold, F. X., Gunther, T. A., and Tay, A. S. (1998). Evaluating density forecasts with applications to financial risk management. International Economic Review, 39(4):863-883.

Diebold, F. X., Hahn, J., and Tay, A. S. (1999). Multivariate density forecast evaluation and calibration in financial risk management: high-frequency returns on foreign exchange. Review of Economics and Statistics, 81(4):661-673.

Diebold, F. X. and Mariano, R. S. (2002). Comparing predictive accuracy. Journal of Business E Economic Statistics, 13(3):253-263. 
Eo, Y. (2009). Bayesian Analysis of DSGE Models with Regime Switching. MPRA Paper, 13910.

Fernández-Villaverde, J., Guerrón-Quintana, P., and Rubio-Ramírez, J. F. (2010). Fortune or virtue: Time-variant volatilities versus parameter drifting in U.S. data. NBER Working Papers, 15928.

Foerster, A. T., Rubio-Ramirez, J. F., Waggoner, D. F., and Zha, T. A. (2014). Perturbation methods for Markov-switching DSGE models. NBER Working Papers, 20390.

Fornari, F. and Stracca, L. (2012). What does a financial shock do? First international evidence. Economic Policy, 27(71):407-445.

Gelain, P. and Ilbas, P. (2014). Monetary and macroprudential policies in an estimated model with financial intermediation. NBB Working Paper, 258.

Gerard, H. and Nimark, K. (2008). Combining multivariate density forecasts using predictive criteria. Technical report, Department of Economics and Business, Universitat Pompeu Fabra, Economics Working Papers, 2008.

Gertler, M. and Karadi, P. (2011). A model of unconventional monetary policy. Journal of Monetary Economics, 58(1):17-34.

Giraitis, L., Kapetanios, G., Theodoridis, K., and Yates, T. (2014). Estimating time-varying DSGE models using minimum distance methods. Bank of England Working Paper, 507.

Gürkaynak, R. S., Kisacikoglu, B., and Rossi, B. (2013). Do DSGE Models Forecast More Accurately Out-of-Sample than VAR Models? CEPR Discussion Papers, (9576).

Herbst, E. and Schorfheide, F. (2012). Evaluating DSGE model forecasts of comovements. Journal of Econometrics.

Hirose, Y. and Inoue, A. (2014). The zero lower bound and parameter bias in an estimated DSGE model. IMES Discussion Paper Series, Bank of Japan, (14-E-09).

Huang, K., Chen, J., Li, Z., and Sun, J. (2014). Financial conditions and slow recoveries. Vanderbilt University Department of Economics Working Papers, 14-00004. 
Hurtado, S. (2014). DSGE Models and the Lucas critique. Economic Modelling, 44(S1):S12 - S19.

Iacoviello, M. (2005). House prices, borrowing constraints, and monetary policy in the business cycle. American Economic Review, 95(3):739-764.

Kling, J. L. and Bessler, D. A. (1989). Calibration-based predictive distributions: An application of prequential analysis to interest rates, money, prices, and output. Journal of Business, 62(4):477-499.

Knüppel, M. (2015). Evaluating the calibration of multi-step-ahead density forecasts using raw moments. Journal of Business and Economic Statistics. Forthcoming.

Kolasa, M. and Rubaszek, M. (2015). Forecasting with DSGE models with financial frictions. International Journal of Forecasting, 31(1):1-19.

Kolasa, M., Rubaszek, M., and Skrzypczyński, P. (2012). Putting the New Keynesian DSGE model to the real-time forecasting test. Journal of Money, Credit and Banking, 44(7):13011324 .

Marcellino, M. and Rychalovska, Y. (2014). Forecasting with a DSGE model of a small open economy within the monetary union. Journal of Forecasting, 33(5):315-338.

Reifschneider, D., Wascher, W., and Wilcox, D. (2013). Aggregate supply in the United States: recent developments and implications for the conduct of monetary policy. Finance and Economics Discussion Series, Federal Reserve Board, 2013-77.

Rosenblatt, M. (1952). Remarks on a multivariate transformation. Annual Mathematical Statistics, 23(3):470-472.

Schorfheide, F., Sill, K., and Kryshko, M. (2010). DSGE model-based forecasting of nonmodelled variables. International Journal of Forecasting, 26(2):348-373.

Sims, C. A. (2002). Solving linear rational expectations models. Computational economics, $20(1): 1-20$. 
Smets, F. and Wouters, R. (2007). Shocks and frictions in US business cycles: A Bayesian DSGE approach. American Economic Review, 97(3):586-606.

Villa, S. (2015). Financial frictions in the Euro Area and the United States: a Bayesian assessment. Macroeconomic Dynamics. Forthcoming.

Wolters, M. H. (2015). Evaluating point and density forecasts of DSGE models. Journal of Applied Econometrics. Forthcoming. 


\section{APPENDIX}

\section{A Data sources and transformations}

This section discusses the sources of the eight observables used in the estimation and their transformation. GDP, GDP deflator inflation, the federal funds rate, civilian population (CNP160V) and civilian employment (CE160V) are downloaded from the ALFRED database of the Federal Reserve Bank of St. Louis. Private consumption expenditures and fixed private investment are extracted from the NIPA Table 1.1.5 of the Bureau of Economic Analysis. Net worth of banks is downloaded from the FRED database and it is computed as the difference between total assets of all commercial banks (TLAACBW027SBOG) and total liabilities of all commercial banks (TLBACBM027SBOG). Average weekly hours worked (PRS85006023) and compensation per hour (PRS85006103) are downloaded from the Bureau of Labor Statistics.

Data are transformed as in Smets and Wouters (2007). In particular, GDP, consumption, investment and net worth are transformed in real per-capita terms by dividing their nominal values by the GDP deflator and the civilian population. Real wages are computed by dividing compensation per hour by the GDP deflator. As shown in the measurement equations, the observable variables of GDP, consumption, investment, wages and net worth are expressed in first differences. Hours worked are multiplied by civilian employment, expressed in per capita terms and demeaned. The inflation rate is computed as a quarter-on-quarter difference of the log of the GDP deflator. The fed funds rate is expressed in quarterly terms. Remaining variables are expressed in 100 times log. All series are seasonally adjusted. In the robustness exercise in Section B, the spread is computed as the difference between the bank prime loan rate and the 3-month Treasury bill rate and it is expressed in quarterly terms. Data on spreads are also extracted from the ALFRED database of the Federal Reserve Bank of St. Louis. 

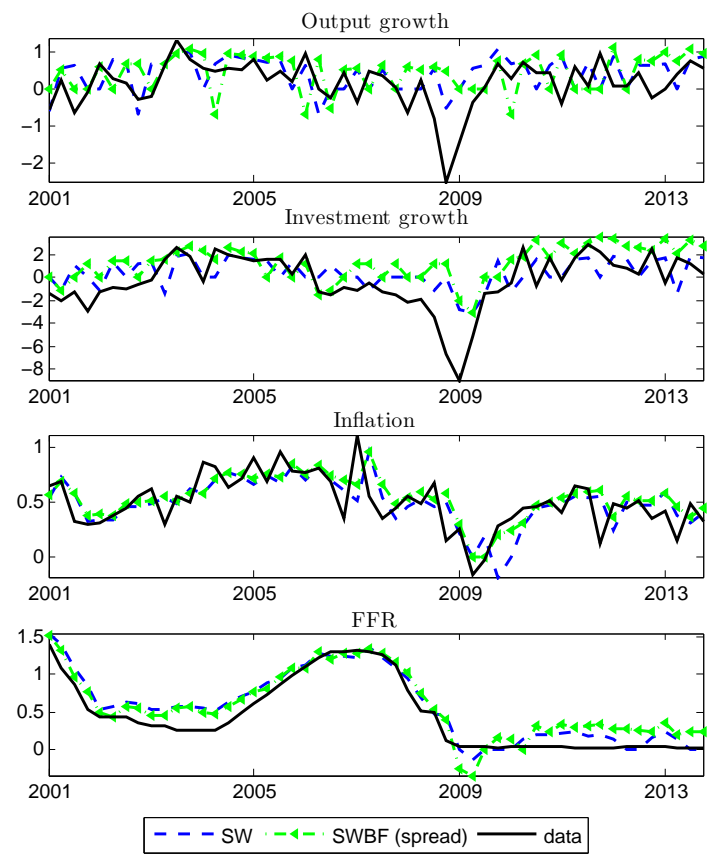

Figure 13: One quarter ahead.

\section{B Evaluating forecasting accuracy with an alternative finan- cial variable}

This section shows the forecasting accuracy of the SWBF model when the observable financial variable is the credit spread instead of net worth. Section B.1 reports the results on the point forecast evaluation, while Section B.2 presents density forecasts.

\section{B.1 Point forecast evaluation}

Figure 13 shows the one quarter forecast series for output growth, investment growth, inflation, and federal funds rate (FFR) for the SWBF and the SW model for the whole forecasting period. The predictions for the two DSGE models are similar to the ones shown in Figure 1. Hence results are robust to the use of the different financial observable variable.

We now compute Mean Forecast Error (MFE). Table 8 shows the MFE of the SWBF model over the period 2001-2008. Results are remarkably similar to the ones in Table 2: there is no bias for consumption; inflation, the nominal interest rate, wage and hours are underpredicted; output and investment are overpredicted. Same rationale applies to the MFE over the period 2009-2013, reported in Table 9. The only difference from Table 3 is 


\begin{tabular}{clllllll}
\hline & Output & Inflation & FFR & Wage & Consumption & Investment & Hours \\
\hline Horizon & & & & & & & \\
1 & -0.23 & $0.17^{* * *}$ & $1.12^{* * *}$ & $0.27^{* * *}$ & 0.01 & $-0.84^{* *}$ & $1.74^{* * *}$ \\
2 & $-0.27^{* *}$ & $0.16^{* * *}$ & $1.00^{* * *}$ & $0.35^{* * *}$ & 0.11 & $-1.17^{* * *}$ & $1.81^{* * *}$ \\
4 & $-0.26^{*}$ & $0.15^{* * *}$ & $0.74^{* * *}$ & $0.24^{* *}$ & 0.12 & $-1.21^{* * *}$ & $1.63^{* * *}$ \\
6 & $-0.35^{* * *}$ & $0.13^{* *}$ & $0.54^{* * *}$ & $0.30^{* *}$ & -0.08 & $-1.27^{* * *}$ & $1.41^{* *}$ \\
8 & $-0.35^{* *}$ & $0.13^{* *}$ & $0.36^{* *}$ & 0.16 & -0.16 & $-1.12^{* * *}$ & 0.89 \\
12 & -0.20 & $0.13^{*}$ & 0.16 & 0.14 & -0.14 & -0.42 & 0.88 \\
\hline
\end{tabular}

Table 8: Mean Forecast Error for the sample 2001Q1-2008Q4 of the SWBF where the credit spread is the financial observable. Asterisks $* * *,{ }^{* *}$ and ${ }^{*}$ denote, respectively, the $1 \%, 5 \%$ and $10 \%$ significance levels.

\begin{tabular}{clllllll}
\hline & Output & Inflation & FFR & Wage & Consumption & Investment & Hours \\
\hline Horizon & & & & & & & \\
1 & 0.00 & $0.38^{* * *}$ & $1.85^{* * *}$ & $0.31^{* *}$ & 0.40 & -1.15 & $8.86^{* * *}$ \\
2 & -0.24 & $0.34^{* * *}$ & $1.74^{* * *}$ & 0.15 & 0.23 & $-1.90^{* * *}$ & $8.80^{* * *}$ \\
4 & -0.26 & $0.31^{* * *}$ & $1.43^{* * *}$ & 0.31 & 0.25 & $-2.55^{* * *}$ & $8.56^{* * *}$ \\
6 & $-0.51^{* * *}$ & $0.30^{* * *}$ & $1.17^{* * *}$ & 0.21 & 0.02 & $-3.35^{* * *}$ & $7.11^{* * *}$ \\
8 & $-0.77^{* * *}$ & $0.27^{* * *}$ & $0.92^{* * *}$ & 0.12 & $-0.25^{*}$ & $-3.48^{* * *}$ & $6.94^{* * *}$ \\
12 & $-0.68^{* *}$ & $0.29^{* * *}$ & $0.51^{* * *}$ & 0.22 & $-0.61^{* * *}$ & $-2.69^{* * *}$ & $4.95^{* * *}$ \\
\hline
\end{tabular}

Table 9: Mean Forecast Error for the sample 2009Q1-2013Q4 of the SWBF where the credit spread is the financial observable. Asterisks $* * *, * *$ and $*$ denote, respectively, the $1 \%, 5 \%$ and $10 \%$ significance levels.

that there is no bias for the wage variable.

Tables 10 and 11 show the RMSFE over the forecasting periods 2001-2008 and 2009-2013, respectively. Differently from Table 4, the forecasting accuracy for inflation is statistically better in the SWBF model for most horizons, while the other results are pretty similar between the two specifications (SWBF model estimated with net worth and the one estimated with the credit spread) also for the sample 2009-2013.

In order to provide some intuition for the results of the point forecasts, we present the recursive estimates of shocks and main parameters in Figures 14 and 15. The shock processes show a lower degree of instability compared to the estimates of the SW model and of the SWBF model (net worth). It should be noted that the volatility of the spread series is more than $90 \%$ lower than the volatility of the net worth series. The risk premium and the net worth shocks are less volatile than in the other two estimated models also from a quantitative point of view. The volatility of the investment-specific technology shock is pretty stable, while that of wage mark-up shock exhibits a clear increasing trend over the recursive sample. The 


\begin{tabular}{clllllll}
\hline & Output & Inflation & FFR & Wage & Consumption & Investment & Hours \\
\hline 1 & 1.40 & $1.01^{* * *}$ & $1.00^{* * *}$ & 0.81 & $1.25^{* *}$ & 1.03 & $1.09^{* *}$ \\
2 & 1.09 & $0.87^{* *}$ & 1.02 & 0.89 & 1.22 & 0.96 & 1.24 \\
4 & 1.28 & $0.86^{* * *}$ & 1.02 & 0.75 & 1.04 & $1.01^{* * *}$ & 1.22 \\
6 & $1.15^{* *}$ & $0.78^{*}$ & 0.99 & 0.91 & 1.08 & $1.03^{* *}$ & $1.22^{* *}$ \\
8 & 1.07 & $0.63^{* * *}$ & 0.96 & 1.02 & 1.11 & $1.25^{* * *}$ & 1.21 \\
12 & $0.99^{*}$ & 0.71 & 0.97 & 0.93 & 1.11 & 1.03 & 1.76 \\
\hline
\end{tabular}

Table 10: Root Mean Square Forecast Error of the SWBF model where the credit spread is the financial observable. All RMSFE are computed as a ratio to the RMSFE in the Smets and Wouters model. Forecasting evaluation period: 2001Q1-2008Q4. Asterisks $* * *, * *$ and $*$ denote, respectively, the $1 \%, 5 \%$ and $10 \%$ significance levels of the Diebold-Mariano test, where the long-run variance is calculated with the Newey-West method.

\begin{tabular}{clllllll}
\hline & Output & Inflation & FFR & Wage & Consumption & Investment & Hours \\
\hline 1 & 1.64 & 0.93 & 0.98 & 1.08 & 1.40 & 1.16 & 1.23 \\
2 & $1.55^{* *}$ & 0.78 & 0.96 & 0.92 & $1.25^{*}$ & 1.39 & 1.20 \\
4 & $1.24^{* *}$ & 0.69 & $0.89^{* *}$ & 1.08 & $0.88^{*}$ & $1.66^{* * *}$ & 1.15 \\
6 & $1.30^{* *}$ & 0.80 & $0.78^{* * *}$ & 0.96 & 1.10 & $1.65^{* * *}$ & 1.07 \\
8 & 1.08 & $0.65^{* * *}$ & $0.68^{* * *}$ & 0.78 & 1.14 & $1.64^{* *}$ & $1.06^{*}$ \\
12 & 1.54 & $0.72^{* * *}$ & $0.51^{* *}$ & 1.15 & 1.14 & 1.47 & $0.94^{* * *}$ \\
\hline
\end{tabular}

Table 11: Root Mean Square Forecast Error of the SWBF model where the credit spread is the financial observable. All RMSFE are computed as a ratio to the RMSFE in the Smets and Wouters model. Forecasting evaluation period: 2009Q1-2013Q4. Asterisks ${ }^{* * *},{ }^{* *}$ and ${ }^{*}$ denote, respectively, the $1 \%, 5 \%$ and $10 \%$ significance levels of the Diebold-Mariano test, where the long-run variance is calculated with the Newey-West method. 

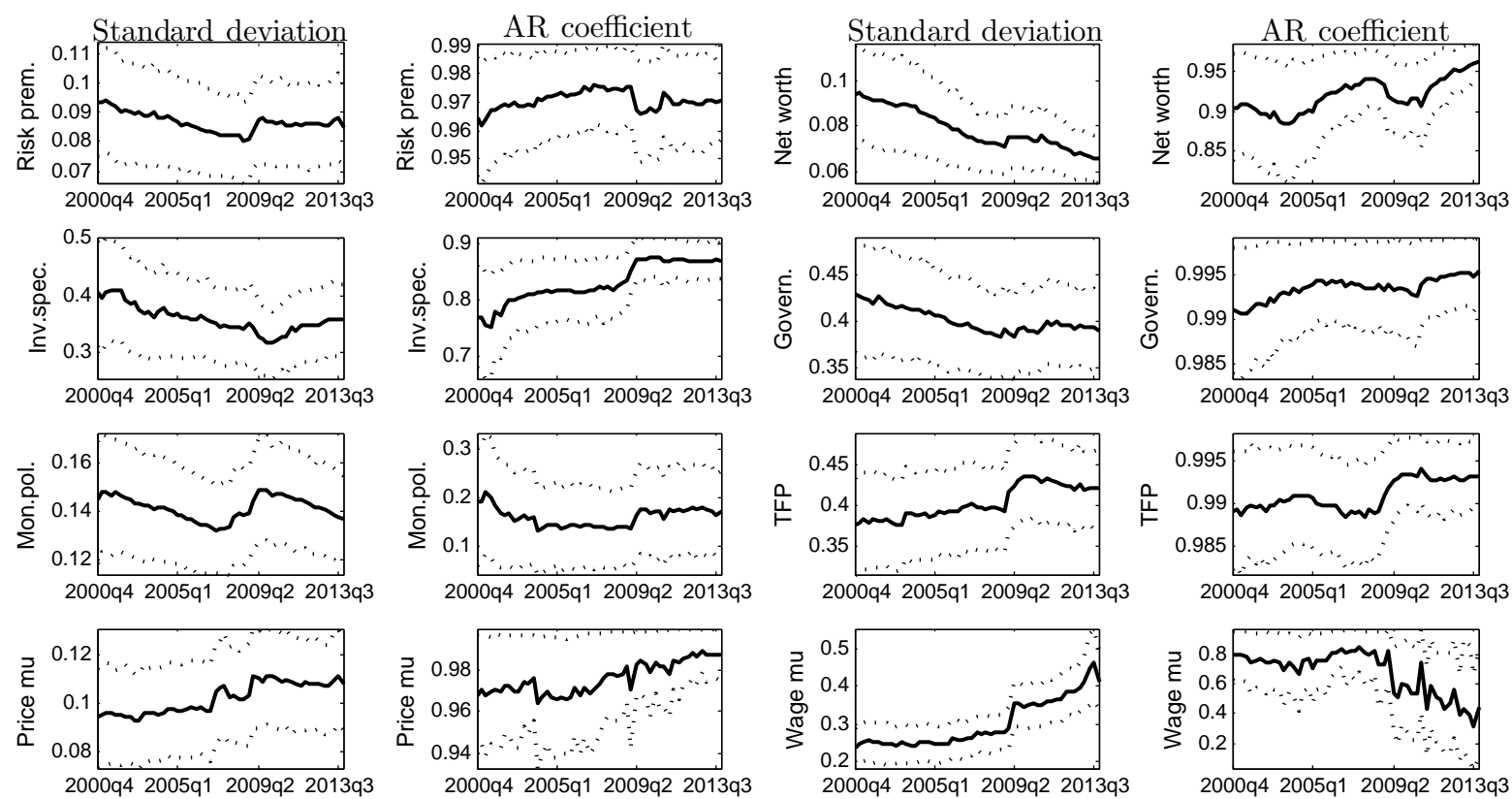

Figure 14: Evolution of the shock processes of the SWBF model, where the observable financial variable is the credit spread. Solid lines represent the posterior mean, while dotted lines 5th and 95th posterior percentiles. Estimates are computed based on the recursive estimation sample starting from 1984Q1-2000Q4 and ending in 2013Q4.

volatility of the TFP shock shows a step in correspondence to the 2009. Recursive estimation of the parameters confirms the lower degree of instability.

Results are robust also for the analysis of the rolling RMSFE. Figure 16 shows the difference between the RMSFE of the SW model and the SWBF model for one step-ahead forecasts. On average the SW model yields better forecast for output growth, but in the starting period and around 2011; while the SWBF model is preferable for forecasting inflation.

\section{B.2 Density forecast evaluation}

Tables 12 and 13 support previous findings: the SWBF model outperforms the SW model in forecasting inflation, FFR and hours, while the contrary happens for output, consumption and investment.

The PITs histograms confirm the pattern already described with the net worth variables. In the whole sample, 2001-2013, the SWBF is better calibrated. Instead, in the period 2009-2013, plots do not report a uniform distribution. 

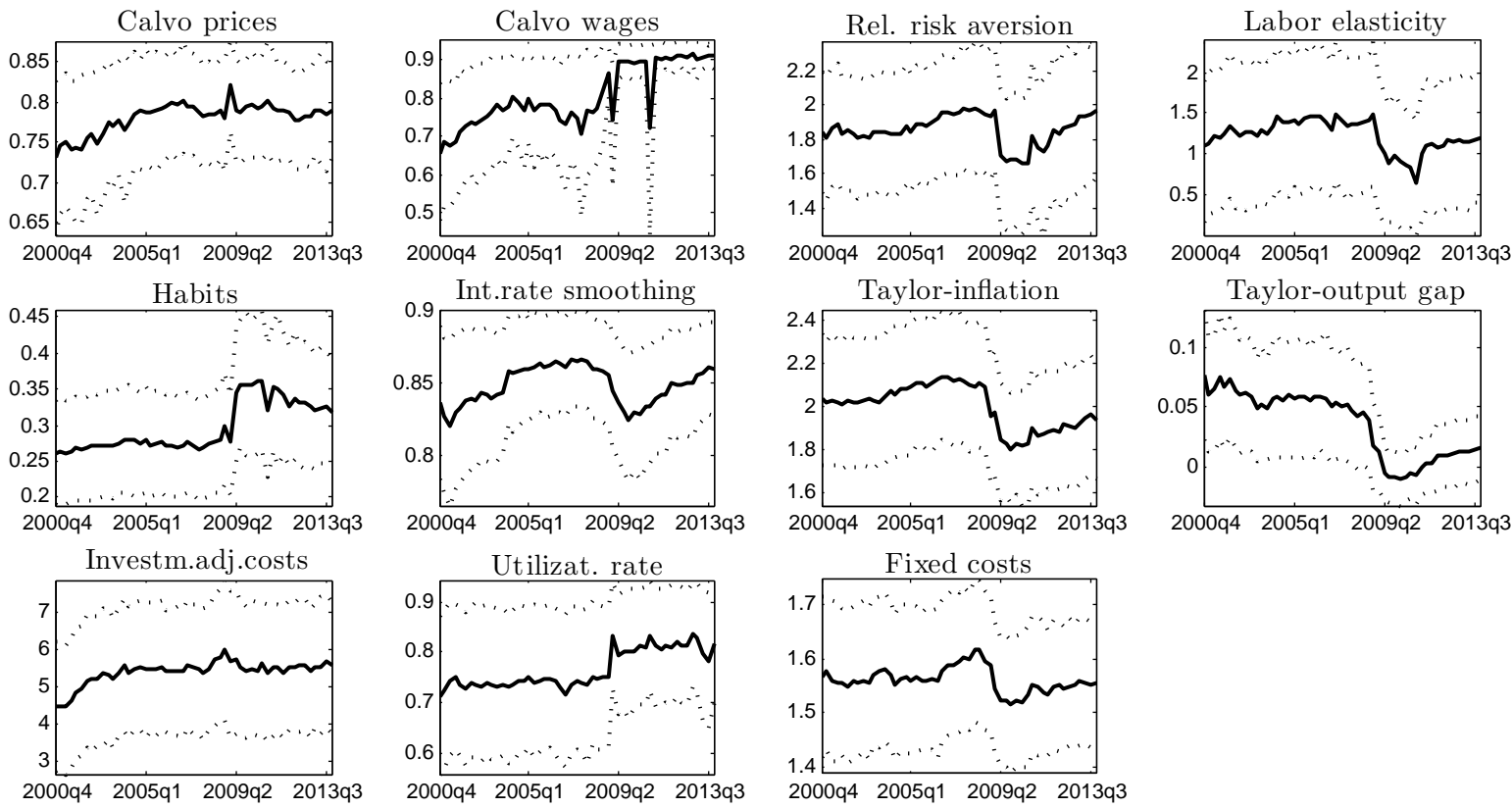

Figure 15: Evolution of the parameters of the SWBF model, where the observable financial variable is the credit spread. Solid lines represent the posterior mean, while dotted lines 5th and 95th posterior percentiles. Estimates are computed based on the recursive estimation sample starting from 1984Q1-2000Q4 and ending in 2013Q4.

\begin{tabular}{clllllll}
\hline & Output & Inflation & FFR & Wage & Consumption & Investment & Hours \\
\hline 1 & -0.11 & 5.60 & 4.29 & 3.35 & -4.28 & 7.77 & 62.68 \\
2 & 5.98 & 6.11 & 5.44 & 0.94 & -7.47 & 28.54 & 60.39 \\
4 & 4.99 & 5.62 & 2.98 & -16.73 & -6.30 & 11.80 & 66.07 \\
6 & 5.93 & 4.27 & 4.19 & -12.97 & -8.36 & -81.29 & 66.32 \\
8 & 0.86 & 5.29 & 2.23 & -10.41 & -8.56 & -113.35 & 61.31 \\
12 & -2.97 & 8.31 & 11.78 & -5.37 & -14.47 & -94.15 & 58.29 \\
\hline
\end{tabular}

Table 12: Percentage improvement in the log predictive scores for the period 2001Q1-2008Q4 over the SW model.

\begin{tabular}{clllllll}
\hline & Output & Inflation & FFR & Wage & Consumption & Investment & Hours \\
\hline 1 & -6.59 & 2.38 & 3.91 & -2.38 & -19.73 & -533.60 & 54.11 \\
2 & -23.75 & 0.96 & 3.44 & 13.95 & -33.30 & -658.82 & 46.89 \\
4 & -36.33 & 1.19 & 17.62 & 8.99 & -15.52 & -614.28 & 110.94 \\
6 & -14.26 & -3.04 & 22.13 & 12.26 & -36.47 & -531.62 & 308.26 \\
8 & -1.17 & -2.30 & 15.42 & 35.79 & -17.61 & -754.96 & 338.02 \\
12 & -20.29 & 1.33 & 25.35 & 31.66 & 11.68 & -869.83 & 519.04 \\
\hline
\end{tabular}

Table 13: Percentage improvement in the log predictive scores for the period 2009Q1-2013Q4 over the SW model. 

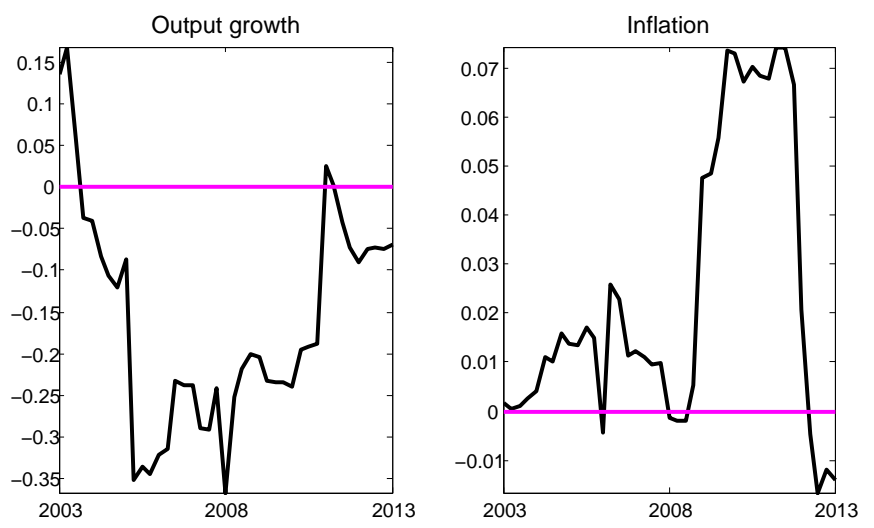

Figure 16: Difference over time in 1-quarter-ahead rolling RMSFEs between the SW and SWBF models for output growth and inflation. At each point in time, the RMSFEs are computed using the previous 12 quarters.
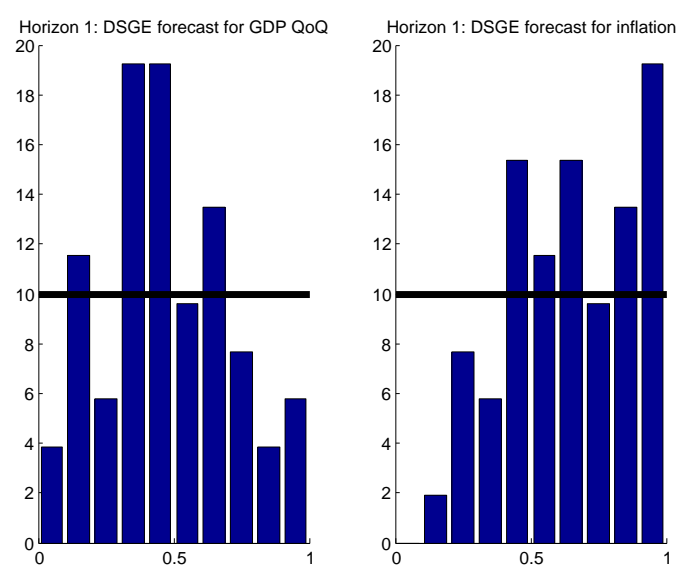

Figure 17: DSGE SWBF Density Forecasts: PIT Histograms for One-Quarter-Ahead Forecasts for the period 2001-2013
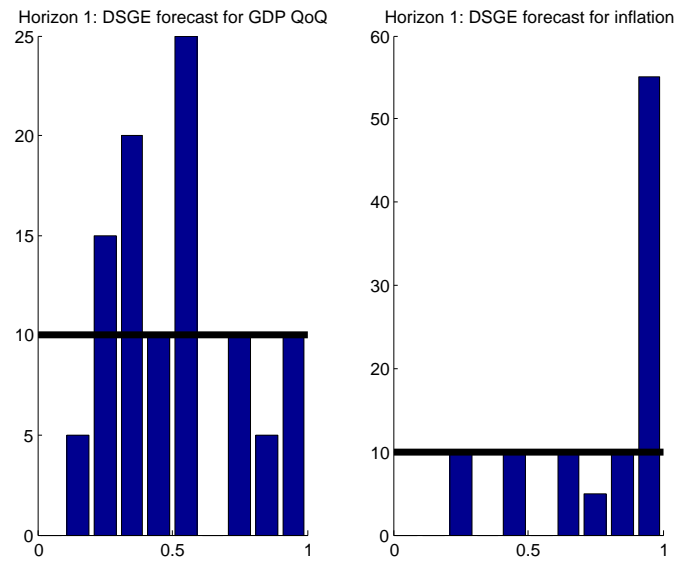

Figure 18: DSGE SWBF Density Forecasts: PIT Histograms for One-Quarter-Ahead Forecasts for the period 2009-2013. 